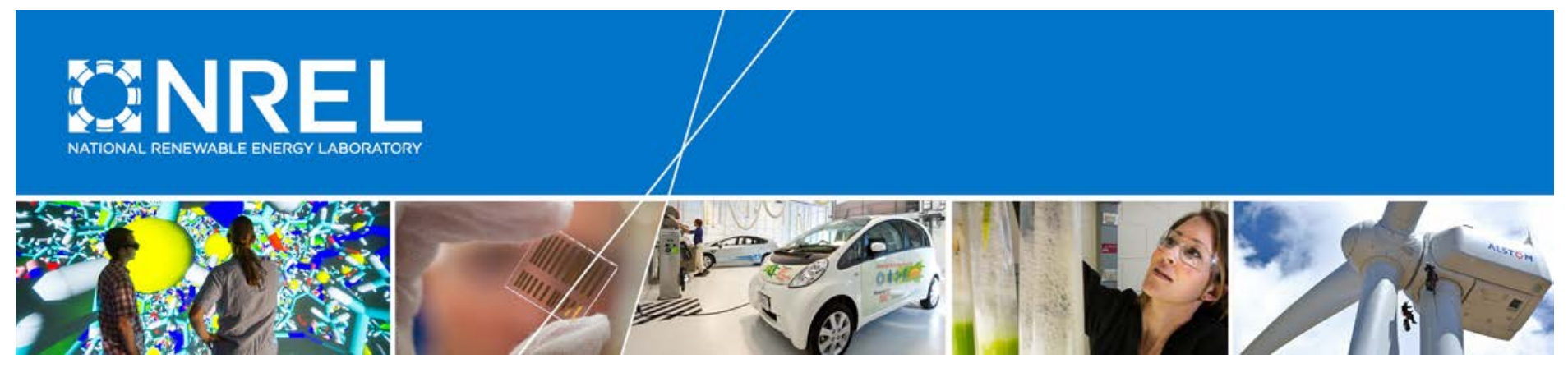

\title{
REopt: A Platform for Energy System Integration and Optimization
}

Dylan Cutler, Dan Olis, Emma Elgqvist, Xiangkun Li, Nick Laws, Nick DiOrio, Andy Walker, and Kate Anderson National Renewable Energy Laboratory

NREL is a national laboratory of the U.S. Department of Energy Office of Energy Efficiency \& Renewable Energy Operated by the Alliance for Sustainable Energy, LLC

This report is available at no cost from the National Renewable Energy Laboratory (NREL) at www.nrel.gov/publications.

Technical Report

NREL/TP-7A40-70022

September 2017 


\section{REopt: A Platform for Energy System Integration and Optimization}

Dylan Cutler, Dan Olis, Emma Elgqvist, Xiangkun Li, Nick Laws, Nick DiOrio, Andy Walker, and Kate Anderson National Renewable Energy Laboratory

Prepared under Task No. FEMP.10960.11.02.06

NREL is a national laboratory of the U.S. Department of Energy Office of Energy Efficiency \& Renewable Energy Operated by the Alliance for Sustainable Energy, LLC

This report is available at no cost from the National Renewable Energy Laboratory (NREL) at www.nrel.gov/publications.

National Renewable Energy Laboratory 15013 Denver West Parkway Golden, CO 80401

303-275-3000 • www.nrel.gov

\section{Technical Report}

NREL/TP-7A40-70022

September 2017

Contract No. DE-AC36-08GO28308 


\section{NOTICE}

This report was prepared as an account of work sponsored by an agency of the United States government. Neither the United States government nor any agency thereof, nor any of their employees, makes any warranty, express or implied, or assumes any legal liability or responsibility for the accuracy, completeness, or usefulness of any information, apparatus, product, or process disclosed, or represents that its use would not infringe privately owned rights. Reference herein to any specific commercial product, process, or service by trade name, trademark, manufacturer, or otherwise does not necessarily constitute or imply its endorsement, recommendation, or favoring by the United States government or any agency thereof. The views and opinions of authors expressed herein do not necessarily state or reflect those of the United States government or any agency thereof.

This report is available at no cost from the National Renewable Energy Laboratory (NREL) at www.nrel.gov/publications.

Available electronically at SciTech Connect http:/www.osti.gov/scitech

Available for a processing fee to U.S. Department of Energy and its contractors, in paper, from:

U.S. Department of Energy

Office of Scientific and Technical Information

P.O. Box 62

Oak Ridge, TN 37831-0062

OSTI http://www.osti.gov

Phone: 865.576.8401

Fax: 865.576.5728

Email: reports@osti.gov

Available for sale to the public, in paper, from:

U.S. Department of Commerce

National Technical Information Service

5301 Shawnee Road

Alexandria, VA 22312

NTIS http://www.ntis.gov

Phone: 800.553 .6847 or 703.605 .6000

Fax: 703.605.6900

Email: orders@ntis.gov 


\section{Executive Summary}

REopt is a techno-economic decision support model used to optimize energy systems for buildings, campuses, communities, and microgrids. The primary application of the model is for optimizing the integration and operation of behind-the-meter energy assets. Formulated as a mixed-integer linear program, REopt solves a deterministic optimization problem to determine the optimal selection, sizing, and dispatch strategy of technologies chosen from a candidate pool such that electrical and thermal loads are met at every time step at the minimum life cycle cost. The candidate pool of technologies typically includes photovoltaics, wind power, solar water heating, solar ventilation air preheating, ground source heat pumps, biomass, waste-to-energy, landfill gas, diesel and natural gas generators and combustion turbines, energy storage, dispatchable loads, and the utility grid.

This report provides an overview of the model, including its capabilities and typical applications; inputs and outputs; economic calculations; technology descriptions; and model parameters, variables, and equations. The model is highly flexible, and is continually evolving to meet the needs of each analysis. Therefore, this report is not an exhaustive description of all capabilities, but rather a summary of the core components of the model. 


\section{Acknowledgments}

Development of the REopt model has benefited from the expertise of many contributors and advisors over the years. The authors gratefully acknowledge the contributions of Travis Simpkins, Mike Helwig, Alexandra Newman, Donna Heimiller, Billy Roberts, Dennis Scott, Owen Roberts, Robi Robichaud, Nick Long, Donald Chung, Jason Couglin, Dave Peterson, Sean Ong, Linda Parkhill, Julieta Giraldez, Danny Martin, Otto Van Geet, Randy Hunsberger, Gregg Tomberlin, Mike Penev, Mike Hillesheim, Kari Burman, Rob Eger, Nick Muerdter, Ted Kwasnik, Jon Falcey, Jason Acosta, and Eric Rose for optimization model development, technology modeling, financial modeling, cost data, load data, resource data, and model validation.

The REopt model has been improved through the guidance and review provided by Nate Blair, Craig Christenson, Ben Polly, Ben Sigrin, Dan Macumber, Jie Zhang, Moncef Krarti, Rob Braun, Robert Brigantic, Tim McDowell, Mike Coddington, Ben Kroposki, Larry Brackney, Jerry Davis, Charlie Gay, Trieu Mai, Aron Dobos, Dan Getman, Steve Gorin, Jim Cale, Adam Warren, John Barnett, Mike Callahan, Rick Marshall, Jesse Dean, Doug Arent, and Robin Newmark.

Finally, we are grateful to all those who helped sponsor REopt model development and analysis. Although many supporters have funded our work over the years, we would like to acknowledge Rachel Shepherd, Brad Gustafson, Tim Unruh, Leslie Nicholls, and Anne Crawley of the U.S. Department of Energy Federal Energy Management Program for their ongoing support of the REopt program. 


\section{List of Acronyms}

$\begin{array}{ll}\text { CAPEX } & \text { capital expenditures } \\ \text { CFM } & \text { cubic feet per minute } \\ \text { CHP } & \text { combined heat and power } \\ \text { COP } & \text { coefficient of performance } \\ \text { DHW } & \text { domestic hot water } \\ \text { DOE } & \text { U.S. Department of Energy } \\ \text { ECM } & \text { energy conservation measure } \\ \text { EE } & \text { energy efficiency } \\ \text { EFT } & \text { entering fluid temperature } \\ \text { GCF } & \text { Gross Capacity Factor } \\ \text { GSHP } & \text { ground source heat pump } \\ \text { IEC } & \text { International Electrotechnical Commission } \\ \text { ITC } & \text { investment tax credit } \\ \text { kW } & \text { kilowatt } \\ \text { LCC } & \text { life cycle cost } \\ \text { LCOE } & \text { levelized cost of energy } \\ \text { LFG } & \text { landfill gas } \\ \text { LMOP } & \text { Landfill Methane Outreach Program } \\ \text { MACRS } & \text { Modified Accelerated Cost Recovery System } \\ \text { MILP } & \text { mixed-integer linear program } \\ \text { MMBtu } & \text { one million British thermal units } \\ \text { MSW } & \text { municipal solid waste } \\ \text { MW } & \text { megawatt } \\ \text { MWh } & \text { megawatt-hour } \\ \text { NPV } & \text { net present value } \\ \text { NREL } & \text { National Renewable Energy Laboratory } \\ \text { O\&M } & \text { operation and maintenance } \\ \text { solar PV } & \text { photovoltaics } \\ \text { PWF } & \text { present worth factor } \\ \text { RE } & \text { renewable energy } \\ \text { SoC } & \text { state of charge } \\ \text { SVP } & \text { solar ventilation air preheating } \\ \text { SWH } & \text { solar water heating } \\ \text { TMY } & \text { typical meteorological year } \\ \text { TOU } & \text { time of use } \\ \text { WTE } & \text { waste to energy } \\ & \end{array}$




\section{Table of Contents}

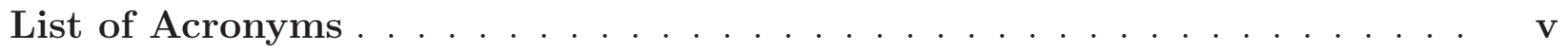

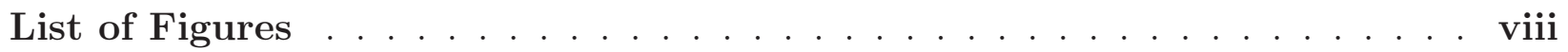

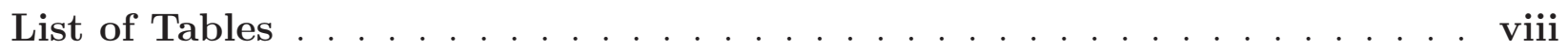

1 Model Overview . . . . . . . . . . . . . . . . . . . . . 1

1.1 General Model Application . . . . . . . . . . . . . . . . . . . . . . . 1

1.2 Overview . . . . . . . . . . . . . . . . . . . . . . . . . 2

1.3 Analysis Capabilities . . . . . . . . . . . . . . . . . . . . 2

1.3.1 Typical REopt Scenarios . . . . . . . . . . . . . . . . . . . 3

1.3.2 Levels of Analysis . . . . . . . . . . . . . . . . . . . . 4

1.4 Mixed Integer Linear Program Formulation . . . . . . . . . . . . . . 6

1.4.1 Objective Function . . . . . . . . . . . . . . . . . 7

1.4 .2 Constraints . . . . . . . . . . . . . . . . . . 7

1.5 Temporal Resolution . . . . . . . . . . . . . . . . . 8

2 Model Inputs and Outputs _. . . . . . . . . . . . . . . . . . . 10

2.1 Inputs . . . . . . . . . . . . . . . . . . . . 10

2.1 .1 Site Data . . . . . . . . . . . . . . . . . . . . . . 11

2.1.2 Thermal and Electrical Load Data . . . . . . . . . . . . . . 11

2.1 .3 Resource Data . . . . . . . . . . . . . . . . . . . . . . . . . . 13

2.1 .4 Cost Data . . . . . . . . . . . . . . . . . . . . . . . . 14

2.1.5 Rate Tariffs, Economic Parameters, and Incentives _. . . . . . . 15

2.2 Outputs . . . . . . . . . . . . . . . . . . 16

3 Economic Model . . . . . . . . . . . . . . . . . . . . . . . . . . . 18

3.1 Definitions, Inputs, and Assumptions . . . . . . . . . . . . . 18

3.2 Ownership Models . . . . . . . . . . . . . . . . . . . . . 20

4 Description of Technologies . . . . . . . . . . . . . . . . . . . . 22

4.1 Variable Technologies . . . . . . . . . . . . . . . . . . . . . . . 22

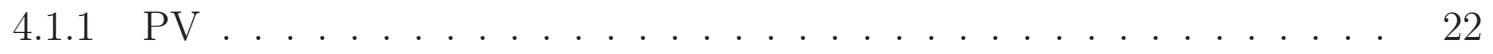

4.1 .2 Wind . . . . . . . . . . . . . . . . . . . . . . . . . . . . . 24

4.1 .3 Solar Water Heating . . . . . . . . . . . . . . . . . . . . 27

4.1.4 Solar Ventilation Air Preheating . . . . . . . . . . . . . . . . . . 30

4.2 Dispatchable Technologies . . . . . . . . . . . . . . . . . . . . . 32

4.2 .1 Utility Grid . . . . . . . . . . . . . . . . . . . . . . . 32

4.2 .2 Generators . . . . . . . . . . . . . . . . . . . . . . . . . . . . 32

4.2 .2 .1 Biomass . . . . . . . . . . . . . . . . . 34

4.2 .2 .2 Landfill Gas . . . . . . . . . . . . . . . . . . . . 35

4.2.2.3 Waste to Energy . . . . . . . . . . . . . . . . . 36

4.2.2.4 Conventional Generators . . . . . . . . . . . . . . 37 
4.2.3 Energy Storage Technologies . . . . . . . . . . . . . . . . . 38

4.3 Energy Conservation Measures . . . . . . . . . . . . . . . . . . . . 40

4.3.1 Ground Source Heat Pumps . . . . . . . . . . . . . . . . . . 41

5 Model Parameters, Variables, and Equations . . . . . . . . . . . . . . . 47

5.1 Indices and Sets . . . . . . . . . . . . . . . . . . . . . 47

5.2 Parameters . . . . . . . . . . . . . . . . . . . . . . 48

5.3 Decision Variables . . . . . . . . . . . . . . . . . . . . . 50

5.4 Objective Function . . . . . . . . . . . . . . . . . . . 52

5.5 Constraints . . . . . . . . . . . . . . . . . . . . 52

5.5.1 Load Constraints . . . . . . . . . . . . . . . . . . . . 53

5.5.2 System Size Constraints . . . . . . . . . . . . . . . . 54

5.5.3 Production Constraints . . . . . . . . . . . . . . 55

5.5.4 Capital Cost Constraints . . . . . . . . . . . . . . . . 56

5.5.5 Minimum Turndown Constraints . . . . . . . . . . . . . 57

5.5.6 Fuel Tracking Constraints . . . . . . . . . . . . . . 58

5.5 .7 Storage Constraints . . . . . . . . . . . . . . . . 58

5.5.8 Demand Rate Constraints . . . . . . . . . . . . . . . . 60

5.5.9 Production Incentive Constraints . . . . . . . . . . . . . . . . 60

5.5 .10 Net Metering Constraints . . . . . . . . . . . . . . . . 61

5.5.11 Net Zero Constraint . . . . . . . . . . . . . . . . 61

A Appendix - Example Costs Assumptions (2016) . . . . . . . . . . 62

References........................... 65 


\section{List of Figures}

Figure 1. Summary of the main inputs to and outputs from the REopt model . . 10

Figure 2. Example of the cost-optimal dispatch strategy for a combined battery

and PV system . . . . . . . . . . . . . . . . . . . 17

Figure 3. Example fuel burn rate curves for diesel generators . . . . . . . . . . . . 38

\section{List of Tables}

Table 1. REopt Analysis Levels . . . . . . . . . . . . . . . . . . 6

Table 2. Assumed Square Footage of Typical Building Types . . . . . . . . . . . . 12

Table 3. Climate Zones and Representative Cities . . . . . . . . . . . . . . 13

Table 4. Energy Data Available for Each Hour and Space Type in Each Climate

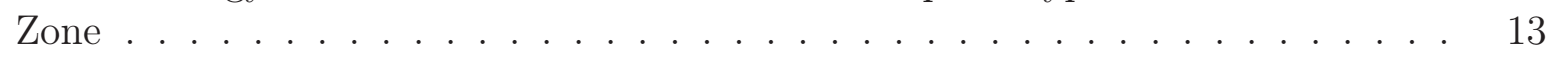

Table 5. $\quad$ Resource Data Source for Various Renewable Energy Technologies . . . . 14

Table 6. Data Sources for Input Economic Parameters . . . . . . . . . . . . . . 15

Table 7. $\quad$ PV - Main Technology Data Sources and Assumptions . . . . . . . . . . 23

Table 8. Specifications of Modeled Wind Turbines . . . . . . . . . . . . . . . . 24

Table 9. Wind - Main Technology Data Sources and Assumptions . . . . . . . . . 27

Table 10. Efficiencies for Different SWH System Sizes . . . . . . . . . . . . . . 28

Table 11. SWH - Main Technology Data Sources and Assumptions . . . . . . . . . 29

Table 12. SVP System Efficiency . . . . . . . . . . . . . . . . . 30

Table 13. SVP - Main Technology Data Sources and Assumptions . . . . . . . . . . 32

Table 14. Biomass Fuel Costs . . . . . . . . . . . . . . . . . . 34

Table 15. Biomass Technology Assumptions . . . . . . . . . . . . . . . . . . 35

Table 16. Landfill Gas Technology Assumptions . . . . . . . . . . . . . . . . . . . 36

Table 17. WTE Technology Assumptions . . . . . . . . . . . . . . . . 37

Table 18. Typical Characteristics of a Lithium-ion Battery Model . . . . . . . . . . 40

Table 19. Typically Assumed GSHP Input Parameter Values . . . . . . . . . . . . 45

Table 20. GSHP - Main Technology Data Sources and Assumptions . . . . . . . . . 46

Table A1. 2016 Default REopt Technology Cost Assumptions . . . . . . . . . . . . 62 


\section{Model Overview}

\subsection{General Model Application}

As renewable energy (RE) and energy efficiency (EE) technologies continue to deliver dependable generation at continually reduced costs, more and more energy consumers are looking to these technologies as cost-effective ways to meet energy needs and increase energy resiliency. To make an effective decision regarding what type and what size of $\mathrm{EE} / \mathrm{RE}$ technology to invest in, there are a myriad of variables one must evaluate (e.g., technology/capital/fixed/variable costs, energy costs, RE resources, and incentives). In the case of dispatchable technologies, such as energy storage, combined heat and power (CHP), and other generators, this problem is even more challenging because the operation of the asset has significant impacts on the economic viability of the technology.

Example scenarios that may arise while evaluating EE/RE opportunities could include:

- An organization has a portfolio of geographically dispersed locations and an RE goal of $30 \%$ renewable energy generation; how should they spend their limited capital resources?

- An organization is interested in photovoltaics (solar PV) and energy storage; is this combination of technologies economically beneficial given their complex rate tariff? And, if so, how should they operate the energy storage system?

- An organization needs to sustain their critical load for 48 hours during a grid outage; what technologies/sizes will provide this resiliency at lowest cost?

- An energy manager at a university campus needs to evaluate what combination of technologies will help achieve the university's carbon reduction goals at minimum cost; what technologies/sizes are recommended and how will their installation impact operation of the university's existing CHP assets?

The REopt model, developed by the National Renewable Energy Laboratory (NREL), was formulated to capture these inputs and decision variables and deliver a cost-optimal solution for meeting a customer's energy requirements while observing all location-specific goals and constraints. The primary application of the model is for optimizing the integration and operation of behind-the-meter energy assets. The REopt platform can be applied to a variety of energy optimization scenarios including renewable energy screenings, campus planning, microgrid design, energy storage analyses, and energy/water optimization. Since 2007, NREL has used versions of this model to evaluate energy opportunities at over 10,000 sites, resulting in over $260 \mathrm{MW}$ of RE deployed. REopt Lite, a simplified online version, is available at reopt.nrel.gov. 


\subsection{Overview}

The REopt model is a techno-economic decision support model used to optimize energy systems for buildings, campuses, communities, and microgrids. Formulated as a mixedinteger linear program, REopt solves a deterministic optimization problem to determine the optimal selection, sizing, and operations strategy of technologies chosen from a candidate pool such that electrical and thermal loads are met at every time step at the minimum lifecycle cost. REopt is a time series model in which energy balances are ensured at each time step (often in 15-minute or 1-hour intervals) and operational constraints are upheld while minimizing the cost of energy services for a given customer. A primary modeling assumption is that decisions made by the model will not impact the markets, i.e., the model is always assumed to be a price-taker. This assumption is in contrast to unit commitment and dispatch models in which pricing is a decision variable. REopt does not model power flow or transient effects.

REopt solves a single-year optimization to determine N-year cash flows, assuming constant production and consumption over all $\mathrm{N}$ years of the desired analysis period. REopt assumes perfect prediction of all future events, including weather and load. The candidate pool of technologies typically include:

- solar PV of various scales/configurations

- energy storage (electrical and thermal)

- wind power (small, medium, and large turbines)

- solar water heating (SWH)

- solar ventilation air preheating (SVP)

- ground source heat pump (GSHP)

- biomass: thermal, CHP, electric

- waste to energy (WTE): thermal, CHP, electric

- landfill gas (LFG): thermal, CHP, electric

- diesel/natural gas generators and combustion turbines

- dispatchable loads/energy conservation measures (ECMs)

- utility grid.

\subsection{Analysis Capabilities}

REopt analyses can be customized to address specific client needs, taking into account different energy goals and the granularity of the data available. The upcoming sections

outline common types of studies performed as well as the level of resolution at which 
analyses can be conducted for different project goals.

\subsubsection{Typical REopt Scenarios}

Common analysis scenarios considered by REopt include (but are not limited to):

- Base case (business-as-usual). In this scenario, the economics of operating the existing system is determined as a benchmark against which all other potential projects are compared. In the base case, the site continues to obtain energy services from existing sources, and no new technologies are considered. The life cycle cost (LCC) of all energy expenditures is calculated by finding the present value of all future energy costs over the analysis period. The net present value (NPV) of any other scenario is the difference between its LCC and the LCC of the base case, which may be positive, negative, or zero depending on the objective.

- Minimize life cycle energy costs. The objective of this scenario is to reduce energy costs by acquiring new energy technologies. If one or more technologies are cost effective, then the present value of the total system costs including future energy costs will be lower than the base case and the resulting NPV will be positive. If no technology is cost effective, the scenario will recommend operating at the businessas-usual case with no new installations and no change in LCC.

- Renewable energy or carbon goals. In this scenario, REopt determines the least-cost pathway to achieving a certain level of renewable energy penetration or carbon reduction within a specified time frame. The solution set consists of all the technologies that achieve this objective at the minimum present value of all future energy and upkeep costs. Depending on resource availability, this scenario may be infeasible or NPV may be negative, indicating that there is a cost to achieving the goal.

- Energy/water optimization. In this scenario, REopt evaluates how water treatment and storage systems can be leveraged for economic savings through demand reduction and time-of-use shifting. REopt looks at water treatment and storage in integration with other energy assets and calculates system sizes and operating strategies to minimize life cycle costs.

- Energy resiliency targets. Energy resiliency scenarios typically require the site to meet some fraction of the total load for a defined grid outage duration using renewable or nonrenewable on-site energy assets. REopt can be used to determine the amount of resiliency and the cost of resiliency goals provided by the addition of new technologies. Because of the explicit modeling of the utility grid within REopt, the model can be used to simulate grid outages by turning off the grid for certain time steps. The load profile can also be modified during these grid outages to represent a "critical" load (either via a percent scaling factor, or by splicing in a critical load). This approach enables evaluation of all technologies in the model, both during grid-connected mode (vast majority of the year) and grid outages when technolo- 
gies may continue to power critical loads as part of a microgrid. This capability is especially important for RE technologies because they are able to generate value during grid-connected mode, while also supporting a critical load during a grid outage (whereas backup generators may only be able to operate during an outage because of regulatory requirements). There are three types of resiliency analysis performed with the REopt model:

1. Optimize for grid-connected benefits and evaluate added resiliency. This approach uses a standard REopt analysis to determine cost-optimal sizing and then performs a large set of runs in which outages are randomly injected into the model. These outages are random in both occurrence and duration, with each variable being sampled independently from a uniform distribution. Outage survivability is then calculated from the results of the large set of runs, wherein survivability is defined as the probability that a site can supply energy to the critical loads for an outage of $X$ hours given a certain set of energy outages.

2. Optimize system sizes for a given outage duration. This approach lets the model optimally size the technologies for grid-connected performance while ensuring that the critical load is met for a given grid outage duration. Typically, multiple runs are performed (all containing the same outage duration, but at different start dates throughout the year) to capture the variability in load and RE resource throughout the year.

3. Include value of resiliency in the objective function. This approach assigns a cost to grid outages (a cost per hour of grid outage), and includes that cost in the objective function. The resiliency each technology is able to deliver (as a function of system size) is calculated in a preprocessing step. Then, REopt is able to consider both reduced grid outage costs and energy generation benefits for all of the technologies in the search space.

These scenarios can be tailored to represent specific client goals or constraints.

\subsubsection{Levels of Analysis}

REopt can be used at various stages of energy projects in an iterative planning process. Initially, REopt can be used to rank and prioritize projects across a portfolio of sites based on limited data. Then, the analysis can be refined in subsequent iterations based on more detailed data sets. At each stage, the analyst determines the appropriate resolution of the analysis to properly balance accuracy of outputs and modeling effort required for a particular analysis goal.

The different levels of analyses are detailed below and summarized in Table 1.

- Level 0: Levelized Cost of Energy (LCOE) Calculation. At the most preliminary analysis level, clients only provide location data for a set of sites. The result is a high-level view of technical and economic viability trends across the portfolio. 
Analyses at this level cannot provide insights into whether or not a particular system is cost effective as current site energy costs are unknown; decisions about projects at specific sites cannot be made.

- Level 1: Screening Analysis. At this level, the client provides data on location; annual electrical and thermal energy consumption and cost; and estimates of roof and land available for renewable energy installations for a set of sites. Information on site-specific constraints may be provided for select locations. The result is a prioritized list of opportunities, including technology type, size, and economics. This list can be used to identify the most viable project opportunities, so clients can selectively allocate additional resources for more detailed analyses to projects with the highest potential for success.

- Level 2: Economic Dispatch Analysis. This analysis is typically done at an individual site or campus. Detailed energy consumption (typically time-series data in 15-minute or hourly resolution) and utility rate tariffs are provided by the site, along with estimates of the space available for renewable energy installations. The site may also provide information on existing energy systems (e.g., types, sizes, operating constraints). Some customization of the model may be required to accurately capture complex utility tariff structures. Additional customization can be done to represent existing equipment or new technologies. The result is a recommendation for technology types, sizes, and dispatch strategies, along with the resulting economics. Project feasibility, energy storage, and resiliency analyses are conducted at this level. 
Table 1. REopt Analysis Levels

\begin{tabular}{|c|c|c|c|c|c|}
\hline Level & Name & $\begin{array}{l}\text { Analysis } \\
\text { Goal }\end{array}$ & Data Required & Outputs & $\begin{array}{l}\text { Technologies } \\
\text { Considered }\end{array}$ \\
\hline 0 & $\begin{array}{l}\text { LCOE } \\
\text { Calcula- } \\
\text { tion }\end{array}$ & $\begin{array}{l}\text { Determine } \\
\text { technical and } \\
\text { economic } \\
\text { viability } \\
\text { trends across } \\
\text { a portfolio of } \\
\text { sites }\end{array}$ & Site location & $\mathrm{LCOE}$ & $\begin{array}{l}\text { PV, wind, } \\
\text { biomass, WTE, } \\
\text { LFG, SWH, } \\
\text { SVP }\end{array}$ \\
\hline 1 & $\begin{array}{l}\text { Screening } \\
\text { Analysis }\end{array}$ & $\begin{array}{l}\text { Prioritize } \\
\text { sites for } \\
\text { feasibility } \\
\text { studies }\end{array}$ & $\begin{array}{l}\text { Site location, annual elec- } \\
\text { tric and thermal consump- } \\
\text { tion and costs, land/roof } \\
\text { availability }\end{array}$ & $\begin{array}{l}\text { Prioritized list } \\
\text { of potential } \\
\text { opportunities } \\
\text { and economics }\end{array}$ & $\begin{array}{l}\text { All of the } \\
\text { above, CHP, } \\
\text { GSHP }\end{array}$ \\
\hline 2 & $\begin{array}{l}\text { Economic } \\
\text { Dispatch } \\
\text { Analysis }\end{array}$ & $\begin{array}{l}\text { Recommend } \\
\text { technology } \\
\text { sizes and } \\
\text { operating } \\
\text { strategies }\end{array}$ & $\begin{array}{l}\text { Site location, 15-minute } \\
\text { load profile, utility rate } \\
\text { tariff, land/roof avail- } \\
\text { ability, additional value } \\
\text { streams (e.g., ancillary } \\
\text { services and demand re- } \\
\text { sponse opportunities), } \\
\text { resiliency requirements, } \\
\text { data on existing systems } \\
\text { (size, efficiency, operating } \\
\text { constraints) }\end{array}$ & $\begin{array}{l}\text { Recommended } \\
\text { technology } \\
\text { types and siz- } \\
\text { ing, operations } \\
\text { strategies, and } \\
\text { economics }\end{array}$ & $\begin{array}{l}\text { All of the } \\
\text { above, con- } \\
\text { ventional } \\
\text { generation, } \\
\text { storage }\end{array}$ \\
\hline
\end{tabular}

\subsection{Mixed Integer Linear Program Formulation}

REopt solves a mixed-integer linear program (MILP), the general form of which is given below (Castillo et al. 2002):

$$
\min \sum_{j=1}^{n} c_{j} x_{j}
$$

Subject to:

$$
\begin{aligned}
\sum_{j=1}^{n} a_{i j} x_{j} & =b_{i} ; \quad i=1,2, \ldots, m \\
x_{j} \geq 0 ; & j=1,2, \ldots, n \\
x_{j} & \in \mathcal{N} ; \quad \text { for all or some } j=1,2, \ldots, n
\end{aligned}
$$

where $\mathcal{N}$ is the set $\{1,2, \ldots\}$. 
The objective function in the REopt model minimizes total life cycle cost, comprised of a set of possible revenues and expenses, over the analysis period subject to a variety of integer and noninteger constraints to ensure that thermal and electrical loads are met at every time step by some combination of candidate technologies. A qualitative overview of the components of the objective function as well as the main constraint categories within the MILP is given here; for detailed mathematical formulation, see Section 5.

\subsubsection{Objective Function}

The objective function of the MILP is to minimize the present value of all energy costs (i.e., the LCC) over the analysis period. Costs considered include:

- Capital costs: Investments made to acquire new energy generation capacity, storage units, and other auxiliary equipment

- Operating expenses: Fixed and variable technology operation and maintenance (O\&M) costs, equipment replacement costs, biomass feedstock costs, fuel costs, utility purchases, and financial losses incurred due to grid outages

- Operating revenues: Net metering income, wholesale electricity sales, productionbased incentives, and WTE tipping fees

- Incentives and tax benefits: Federal, state, and utility incentives, accelerated depreciation schedules.

Cash flows during the analysis period are found by first escalating the present costs at project-specific inflation and utility cost escalation rates, then discounting back to the present using a client-determined discount rate.

\subsubsection{Constraints}

The constraints governing how REopt builds and dispatches technologies fall into the following categories:

- Load constraints. Electrical and thermal loads must be fully met by some combination of renewable generation, fossil fuel generation, and storage during every time step. Typically, hourly or 15-minute time steps are used in the model, yet for screening applications a typical day per month may be modeled (and scaled to correctly account for full-year economics) to reduce computational complexity when evaluating the full spectrum of technologies. Additional load constraints restrict the amount of energy that a particular technology can replace. For example, solar water heating can only replace the energy that is used to heat domestic hot water.

- Resource constraints. The amount of energy that a technology can produce is limited by the amount of resource available within a region or by the size of fuel storage systems. Biomass and WTE technologies, for example, may only consume 
the material within close proximity of the plant. The energy production of variable technologies is limited by the renewable resource at the location, whereas the utility grid is assumed to be able to provide unlimited amounts of energy (although outages can be simulated by not allowing the grid to meet energy needs for certain periods).

- Operating constraints. Dispatchable technologies such as biomass, WTE, LFG, and fossil generators may have minimum turndown limits that prevent them from operating at partial loads less than a specified level. Other operating constraints may limit the number of times a dispatchable technology can cycle on and off each day, or impose minimum or maximum state-of-charge requirements on battery technology.

- Sizing constraints. Most sites have limited land and roof area available for renewable energy installations, which may restrict the size of technologies like solar PV, wind, SWH, and SVP. LFG is limited by the gas generation of the nearest candidate landfill. The client may also specify acceptable minimum and maximum technology sizes as model inputs.

- Policy constraints. Utilities often impose limits on the cumulative amount of renewable generation a site can install and still qualify for a net metering agreement. Similarly, interconnection limits may restrict the total amount of renewable energy systems that may be connected to the grid. Other policy constraints may restrict the size of a variable technology system in order for it to be eligible for a production incentive.

- Emissions constraints (optional). Carbon dioxide and other greenhouse gases are tracked in REopt and constraints may be included such that the solution meets specified emissions targets.

- Scenario constraints (optional). Net zero electricity constraints require a site to produce as much electricity from renewable generation over the course of a year as it consumes. Similar constraints may require a site to obtain a specified percentage of its total energy from renewable generation or achieve some measure of energy security by meeting the critical load for a defined period of time with on-site generation assets.

\subsection{Temporal Resolution}

REopt uses time series integration to combine the energy production from concurrently operating technologies. The optimization model assumes that production and consumption are constant across all years of analysis, and so only considers the energy balance of year 1. The typical time step is 1 hour, resulting in 8,760 time steps in a typical N-year analysis. This approach ensures that seasonal variation in load and resource availability is captured.

To simplify the complexity for lower fidelity screenings of multiple sites, 288 time steps (24 hours/day x 12 days) are used such that a typical 24-hour day is included for each month. 
Detailed analysis using 35,040 time steps can be performed when 15-minute load and resource data are available. In each of these cases, financial impacts of each time step are scaled to correctly value each time step, ensuring that life cycle calculations are accurately assessed. 


\section{Model Inputs and Outputs}

The main inputs to and outputs from the REopt model are shown in Figure 1. Inputs can be broadly classified into three categories: site-specific data including current consumption across all loads, technology options and their corresponding resource data, and other drivers of the optimization, such as client goals and economic considerations. Details of how REopt obtains and uses each input within the model are described in Section 2.1. The main outputs of REopt typically include optimally selected and sized technologies, dispatch strategies, and various financial parameters over the project life cycle; these are expanded upon in Section 2.2.

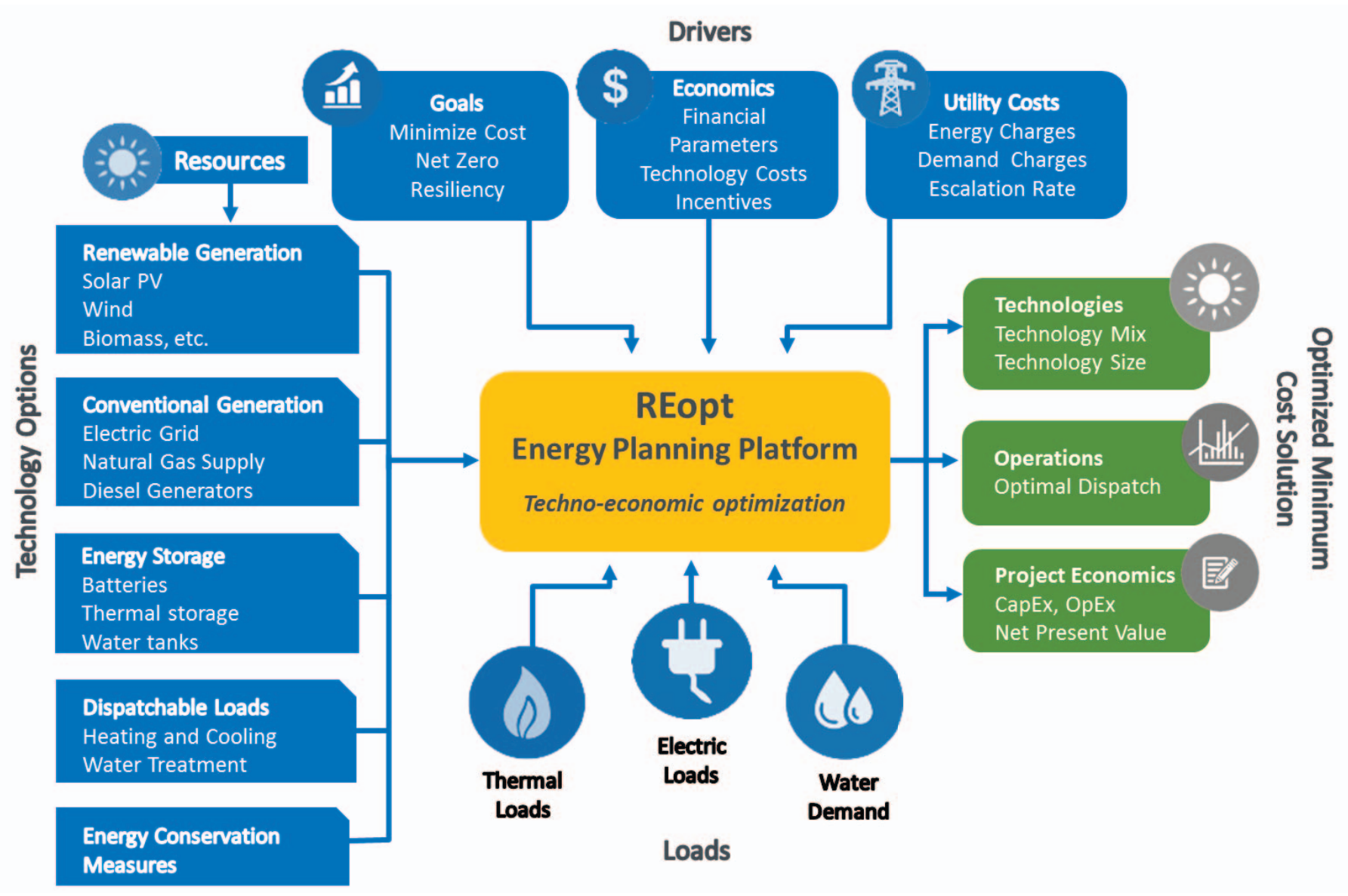

Figure 1. Summary of the main inputs to and outputs from the REopt model

\subsection{Inputs}

A combination of site-specific data as well as internal and external databases are used to obtain the inputs to the REopt model. The following sections summarize the main components and data sources for each input type. 


\subsubsection{Site Data}

Site data is provided by the client for each site under consideration. The information requested can be broken down into the following categories:

- Geospatial data. Latitude and longitude coordinates are used to query for renewable energy resource availability and to account for climate impacts on load profiles. This information is also used to identify any available federal, state, and utility tax incentives as well as the applicable net metering and interconnection limits for each site.

- Energy consumption and costs. Recent-year energy consumption data are required, preferably hourly or subhourly meter interval data when available. Alternatively, annual or monthly kilowatt-hour (kWh) totals can be used to inform simulated load profiles. Energy costs (for electricity in $\$ / \mathrm{kWh}$ and $\$ / \mathrm{kW}$ or thermal consumption in $\$ / \mathrm{MMBtu}$ ) are usually taken from utility bills or through review of the client's utility rate tariff.

- Building type and size. Building specifications are used to estimate space available for building-located technologies such as SVP, and to simulate load profiles if hourly or subhourly data are not available. Building type impacts the shape of the load profile, which can then influence the alignment of the demand and generation of certain technologies. Building size influences both total consumption and available roof area, which impacts the technology size a site can effectively install.

- Space available. Land and rooftop area available for renewable energy projects are used to limit the maximum size of certain technologies like PV and wind turbine generators. If land available is not provided, REopt assumes unlimited availability. If rooftop area available is not provided, REopt estimates rooftop space from building square footage, assuming two-story buildings, with $25 \%$ of rooftop space available for renewable energy projects.

Not all site information is required to conduct an analysis; see Section 1.3.2 for the types of analyses possible given the detail of the site data provided.

\subsubsection{Thermal and Electrical Load Data}

REopt is designed to consider the entire energy consumption of a site, including electricity and any fuel types used (e.g., natural gas, propane, $\# 2$ fuel oil, \#6 fuel oil, and coal). Actual hourly or 15-minute interval load data are used when available. When sites do not have detailed load profile information, REopt queries a local database of EnergyPlus simulations based on building type (or a mix of building types in the case of a campus or installation) and climate zones to obtain a simulated hourly load profile.

REopt synthesizes time-series load profiles for each site by scaling the load profile obtained from the U.S. Department of Energy (DOE) Commercial Reference Buildings data set (Office of Energy Efficiency and Renewable Energy 2017) in proportion to the available 
annual or monthly consumption data. When combining multiple building types to generate a single campus-type load, the energy consumption values from each building type can be normalized to a per-unit area basis using the building areas shown in Table 2 and then combined based on percentages entered by the user.

Table 2. Assumed Square Footage of Typical Building Types

\begin{tabular}{lc}
\hline Space Type & Name Area $\left(\mathrm{ft}^{2}\right)$ \\
\hline Full-Service Restaurant & 5,500 \\
Hospital & 241,351 \\
Large Hotel & 122,120 \\
Large Office & 498,588 \\
Medium Office & 53,628 \\
Midrise Apartment & 33,740 \\
Outpatient Clinic & 40,946 \\
Primary School & 73,960 \\
Quick-Service Restaurant & 2,500 \\
Secondary School & 210,887 \\
Small Hotel & 43,200 \\
Small Office & 5,500 \\
Stand-Alone Retail & 24,962 \\
Strip Mall & 22,500 \\
Supermarket & 45,000 \\
Warehouse & 52,045 \\
\hline
\end{tabular}

The EnergyPlus simulations consider 15 climate zones (Table 3) and 16 different commercial reference building types (Table 2) within each climate zone. These building types represent an estimated $70 \%$ of the national commercial building stock.

An hourly energy consumption profile for the typical meteorological year (TMY) is then reported for each building type in each climate zone. Energy consumption is further subdivided into the following categories: electricity, cooling, electric heating, fuel heating, and hot water demand. Table 4 summarizes the breakdown of the available energy data. 
Table 3. Climate Zones and Representative Cities

\begin{tabular}{cl}
\hline Climate Zone & TMY Location \\
\hline 1A & Miami, Florida \\
2A & Houston, Texas \\
2B & Phoenix, Arizona \\
3A & Atlanta, Georgia \\
3B & Los Angeles, California \\
3C & San Francisco, California \\
4A & Baltimore, Maryland \\
4B & Albuquerque, New Mexico \\
4C & Seattle, Washington \\
5A & Chicago, Illinois \\
5B & Boulder, Colorado \\
6A & Minneapolis, Minnesota \\
6B & Helena, Montana \\
7 & Duluth, Minnesota \\
8 & Fairbanks, Alaska \\
\hline
\end{tabular}

Table 4. Energy Data Available for Each Hour and Space Type in Each Climate Zone

\begin{tabular}{ll}
\hline Field & Description \\
\hline Electricity & Total building electricity usage \\
Electric Cooling & Considers only electric cooling \\
Electric Heating & Considers only electric heating \\
Fuel Heating & Reports heating energy generated from fuel sources \\
Hot Water & Includes all hot water energy demand \\
\hline
\end{tabular}

\subsubsection{Resource Data}

REopt automatically queries NREL's geographic information system databases to gather renewable energy resource data. This information is used to calculate the production profiles of various technologies. Table 5 shows the sources of the resource data for the renewable energy technologies considered in REopt. For more details of the resource data used, refer to the specific technology description sections in Section 4. 
Table 5. Resource Data Source for Various Renewable Energy Technologies

\begin{tabular}{ll}
\hline Technology & Resource Data \\
\hline Solar PV & $\begin{array}{l}\text { Hourly solar irradiance values are from TMY2 data from the 1991-2005 } \\
\text { National Solar Radiation Database (Wilcox 2007) }\end{array}$ \\
\hline Wind & $\begin{array}{l}\text { Hourly wind speeds and air densities at different elevations are obtained } \\
\text { from AWS Truepower }\end{array}$ \\
\hline SWH & $\begin{array}{l}\text { Ambient temperature and solar irradiance are obtained from TMY3 data } \\
\text { from the closest weather station }\end{array}$ \\
\hline SVP & $\begin{array}{l}\text { Heat savings potential is obtained through internal NREL model- } \\
\text { ing (National Renewable Energy Laboratory 1998) and hourly solar ir- } \\
\text { radiance values are from TMY3 data from the closest weather station }\end{array}$ \\
\hline GSHP & $\begin{array}{l}\text { Ambient temperatures are obtained from TMY3 data and used to inform } \\
\text { technology performance assumptions }\end{array}$ \\
\hline Biomass & $\begin{array}{l}\text { Tons of biomass available within a 25- and 50-mile radius are obtained } \\
\text { from NREL's "A Geographic Perspective on the Current Biomass Resource } \\
\text { Availability in the United States" (Milbrandt 2005) }\end{array}$ \\
\hline WTE & $\begin{array}{l}\text { Tons of municipal solid waste (MSW) available within a 25-mile radius are } \\
\text { obtained from BioCycle Journal's "State of Garbage in America" (Haaren, } \\
\text { Themelis, and Goldstein 2010) }\end{array}$ \\
\hline LFG & $\begin{array}{l}\text { Candidate landfill locations and potential energy generation are obtained } \\
\text { from the Environmental Protection Agency's Landfill Methane Outreach } \\
\text { Program (EPA 2017) }\end{array}$ \\
\hline
\end{tabular}

\subsubsection{Cost Data}

NREL maintains a cost data set containing capital, O\&M, and variable operating costs for each technology. It is based on market data, NREL cost research, past trends, published estimates, experts in the field, and actual costs of recently constructed projects. Costs reflect U.S. national averages and include assumed contracting costs for design, supervision, and contingency. Grid upgrade and interconnection costs are not included. This cost data set is used by default, but analysis-specific costs are used when recent quotes or region-specific cost estimates are available.

REopt uses a segmented, piece-wise linear system cost curve to account for the economies of scale realized when constructing larger systems. The slope of each segment of the cost curve represents the marginal cost at that system size range. The marginal cost represents the cost to add the next incremental unit of nameplate capacity to the system in each of the segments. This is combined with the total cost of the previous segments to determine a total system cost for a given system size. The unit cost of the system can then be derived. 
Cost data are regularly updated; for an example of 2016 cost assumptions see Appendix A.

\subsubsection{Rate Tariffs, Economic Parameters, and Incentives}

REopt supports complex tariff structures that include both peak demand charges and time of use (TOU) consumption rates. Demand rates may be specified for on-peak and off-peak hours, which can vary by season. TOU consumption rates may vary by the time of day, the season, or both. Rates are queried from the OpenEI Utility Rate Database as well as the utility websites themselves.

A matrix of energy escalation rates based on fuel type and region is obtained from the National Institute of Standards and Technology, or through consultation with the local utility. The appropriate discount rate is selected in consultation with the client.

REopt obtains incentive information, default net metering limits, and interconnection limits from the Database for State Incentives in Renewable Energy (DSIRE) and models the resulting value of the energy produced and consumed accordingly (DSIRE 2017).

REopt considers any available federal, state, and local incentives for each technology, including cost-based incentives, production-based incentives, and tax incentives. Cost-based incentives are modeled in units of dollars per kilowatt or percent of installed cost, and a maximum total incentive value and maximum system size may be specified. Productionbased incentives are modeled in units of dollars per kilowatt-hour generated per year, and a maximum number of years the incentive is available for, as well as a maximum incentive value per year and system size may be specified. Net metering benefits are also considered, and the value of exported energy as well as maximum system sizes eligible for net metering may be specified. Interconnection limits that restrict the size of distributed generation systems that can be interconnected to the grid may also be specified.

Table 6 summarizes the data sources for REopt's economic inputs. See Section 3 for a detailed description of the economic modeling done within REopt.

Table 6. Data Sources for Input Economic Parameters

\begin{tabular}{ll}
\hline Data & Source \\
\hline Incentives & DSIRE \\
$\begin{array}{l}\text { Net Metering and Intercon- } \\
\text { nection Limits }\end{array}$ & DSIRE \\
Utility Rate Structure & OpenEI Utility Rate Database (OpenEI 2017), utility \\
& $\begin{array}{l}\text { website } \\
\text { Energy Cost Escalation Rates }\end{array}$ \\
& $\begin{array}{l}\text { National Institute of Standards and Technology } \\
\text { (Lavappa, Kneifel, and O'Rear 2017) }\end{array}$ \\
General Inflation Rate & National Institute of Standards and Technology \\
Discount Rate & Client consultation \\
Income Tax Rate & Client consultation \\
\hline
\end{tabular}




\subsection{Outputs}

REopt is highly customizable to the needs of each project. A list of possible outputs includes:

- Optimal technologies and technology sizes for a site. REopt identifies the types and sizes of renewable and conventional energy technologies that meet site goals at the minimum LCC. The LCC is guaranteed optimal to within a known gap (typically $0.01 \%$ ) subject to modeling assumptions. Multiple technologies may be selected or none may be sized to indicate they are not economically viable at the site under consideration.

- Operations strategy. REopt provides the cost-optimal dispatch strategy for operating the recommended technologies at maximum economic efficiency (see Figure 2 for an example dispatch).

- Financial metrics. In addition to the LCC, many financial factors are calculated by REopt to provide insights into the viability of different projects, including the NPV of systems, the capital costs of new technologies before and after the application of incentives, the LCOE for each technology, annual O\&M costs, fuel requirements and costs, and revenue streams generated from energy exported to the utility.

- Prioritized list of projects across a portfolio of sites. REopt compares the NPVs of projects across multiple sites to prioritize which sites a client should target for further study.

- Resiliency metrics. REopt quantifies the amount of time a site can survive a grid outage.

- Sensitivity analysis results. REopt can be used to run thousands of scenarios to evaluate the effects of varying specific inputs (e.g., technology costs, utility escalation rates, and other assumptions) on NPV. 


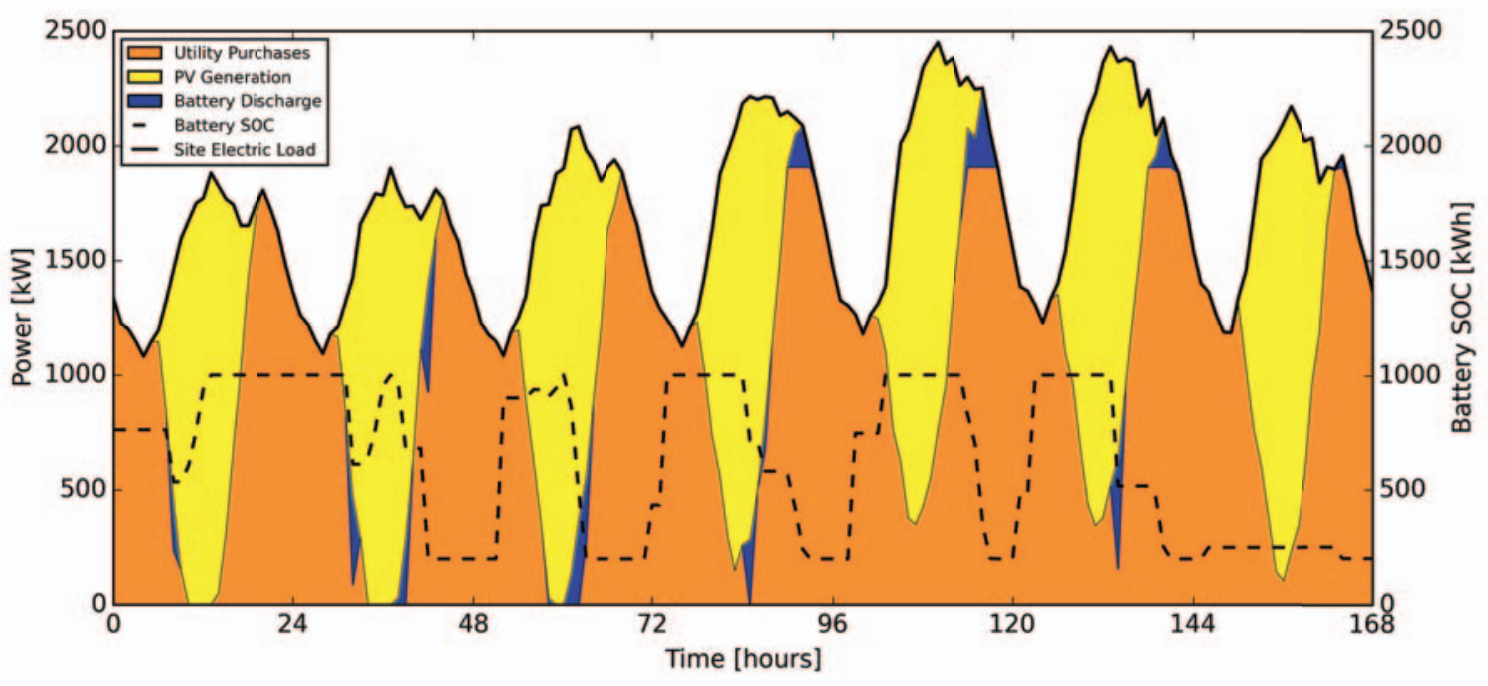

Figure 2. Example of the cost-optimal dispatch strategy for a combined battery and PV system 


\section{Economic Model}

The economic cost-benefit analysis within REopt is based on general economic theory. The approach and terminology are based on the "Manual for the Economic Evaluation of Energy Efficiency and Renewable Energy Technologies" (Short, Packey, and Holt 1995) and abides by the life cycle cost methods and criteria for federal energy projects as described in the "Federal Code of Regulations 10 CFR Part 436 - Subpart A", and which are detailed in NIST Handbook 135, "Life-Cycle Costing Manual for the Federal Energy Management Program" (Fuller and Petersen 1995).

\subsection{Definitions, Inputs, and Assumptions}

The primary economic calculations considered are the NPV of the alternative energy project and the total LCC. $\mathrm{LCC}^{1}$ is the present value of all costs, after-taxes, and incentives, associated with each project option. $\mathrm{NPV}^{2}$ is the present value of the savings (or costs if negative) realized by the project. The objective of the optimization is to minimize LCC. LCC is chosen as the optimization parameter because it is the best economic parameter for selecting among mutually exclusive alternatives and it also maximizes savings. See Short et al. for further discussion. The general equation for NPV is given below:

$$
\text { NPV of alternative }=\text { LCC of Base Case - LCC of Alternative Energy Case }
$$

Here, Base Case refers to the total cost of energy services over the analysis period if the site continues to purchase energy services solely from its existing suppliers. These are typically the site's existing serving utility, but if on-site energy systems exist, those are also included in the Base Case. For example, solar PV systems or CHP plants already in service at the site are modeled to ensure the Base Case scenario properly represents the site's current utility demand, supply sources, and costs. Life-cycle utility costs include annual cost escalation rate projections specific to and specified by the client. For federal clients, utility cost escalation rates are taken from the NIST publication "Energy Price Indices and Discount Factors for Life-Cycle Cost Analysis" (Rushing, Kneifel, and Lippiatt 2013), as revised each year, or as provided by client.

The Alternative Energy Case is the project scenario with additional alternatives to continuing the business-as-usual operation of the Base Case. The Alternative Energy Case considers:

- capital expenditures (CAPEX) of the alternative project

- O\&M costs of the alternative project

- The cost of fuel (e.g., biomass feedstock) or WTE tipping fees collected by the project

${ }^{1} \mathrm{LCC}$ or total life cycle cost has the meaning as described in Short et al., where it is abbreviated as TLCC.

${ }^{2} \mathrm{NPV}$ as described here has the same meaning as net savings, as described in Handbook 135. 
- All applicable incentives made available by utilities, states, or the federal government (e.g., investment tax credit (ITC), production tax credit, and accelerated depreciation)

- Balance of remaining utility costs if the alternative project considered does not supply all of the site's energy loads.

Costs that occur in years beyond the base year (Year 0) are discounted using a present worth factor (PWF). An end-of-year discounting convention is applied. The PWF function properly discounts for:

1. One-time future costs (e.g., a solar PV system's inverter replacement in Year 15 if it is included in the O\&M forecast)

2. Annual recurring costs (e.g., regular annual maintenance for a wind turbine in a real economic analysis)

3. Annual recurring costs that are escalating at a fixed rate each year (e.g., an annual utility cost escalation rate is applied to the base year utility costs to account for projected utility rate increases).

With these considerations in mind, the primary economic inputs into the REopt model are as follows:

- Current utility costs and assumed utility cost escalation rates

- Length of the analysis period

- Discount rate

- Income tax rate

- General inflation rate

- Tax and nontax-based incentives depending on the client's tax disposition.

To calculate the economic outputs, REopt makes the following assumptions:

- CAPEX is considered overnight costs (i.e., all projects are completed at the end of Year 0 and produce energy starting in Year 1) and assumed to be the same in both ownership models (see Section 3.2). Construction periods and construction loans are not modeled.

- A site's annual electric and thermal load demand profiles remain constant from year to year for the duration of the analysis period.

- One year discounting periods are used (i.e., no midyear discounting subperiods).

- All cash flows occur at end of year.

- For tax-paying entities, impacts of alternative energy projects on avoided utility 
costs and project O\&M are considered in after-tax dollars.

- When tax benefits are considered, the system buyer has sufficient tax appetite to capture all available tax incentives in their entirety.

- O\&M costs, biomass feedstock costs, and WTE tipping fees escalate at the general inflation rate.

- Sales tax, insurance costs, and property taxes are not considered.

- Debt service coverage and reserve requirements are not considered.

Real or nominal analyses can be performed as long as discount rates, general inflation, and utility cost escalation rates are consistently represented in real or nominal terms. For technologies that have unequal useful lives (e.g., a 10-year battery versus a 25-year PV system), adjustments are made to ensure that necessary equipment replacements within the analysis period are accounted for and any residual value at the end of the analysis period are captured. Future costs and residual values are appropriately discounted for NPV calculations. Residual value is typically found by assuming straight-line depreciation over the useful life.

\subsection{Ownership Models}

Many economic or pro forma financial analyses consider project options only from the perspective of the project owner, assuming that the party that consumes the energy from an energy-producing technology also purchased, owns, and operates the system. However, on-site renewable energy and nonrenewable energy systems are often financed and owned by an unrelated party that does not consume the energy output but instead sells these energy services to the owner of the building or site. In this type of business arrangement, the site is host to the project and acts as the "off-taker" of the energy, whereas the second party is the project owner or "developer".

A site owner may consider a project of this type if they do not have or do not want to use their own funds to build energy systems, or if they do not want to take on ownership overhead. In this case, clients want to know if a project is economically feasible if a second party builds and operates the system at the client's site and sells the energy services to the client. Business arrangements of this type are sometimes referred to as alternative financed projects and include power purchase agreements, energy savings performance contracts or utility energy service contracts.

REopt is formulated to allow techno-economic screenings of projects for clients under either or both of the following general ownership models:

1. Single-Party Economic Model. The client is interested in projects that they will purchase, own, operate, and consume energy from. This is the conventional ownership model described in the references. The economic screening here answers the question: should the client consider buying additional energy systems to displace 
energy purchases from their existing utility and/or other existing assets?

2. Two-Party Economic Model. The client is interested in procuring energy services from a second party that owns and operates the system(s) on or adjacent to the client's property, and sells the energy produced to the client. Here, there are two parties: the developer and the off-taker. The client is the system off-taker, or consumer of the energy from the project. The developer builds and operates the systems and sells energy services to the off-taker. The developer is an unrelated party who invests in the project as a business venture. The economic screening here answers the question: should the client consider engaging an energy services provider to procure electricity or heat to reduce total costs of energy paid to their conventional utility providers or to consume electricity or heat provided by other existing assets?

The two-party model of ownership uses the same general economic principles as the first, but considers two sets of discount rates and tax rates: 1) the developer's discount rate and tax rate for evaluating ownership costs and revenues necessary for the project to be a sound investment for the developer, and 2) the off-taker's discount rate and tax rate to determine the economic merits of procuring energy services from the project developer instead of the serving utility. Alternative financing projects are complex and will ultimately be evaluated using complex pro formas depending on the financing approach taken. The two-party model in REopt is a simplified screening level analysis to identify potential opportunities for clients considering alternative financing.

The two-party model screens projects that the client would engage in under an alternative financing plan (e.g., through a power purchase agreement or an energy savings performance contract). The model considers the perspective of both the developer and the off-taker. The general approach is as follows:

1. Find the total LCC of the project using the project developer's discount rate, tax rate, and all incentives available to the developer as the project owner.

2. Determine the annual payment (annuity) for energy services required by the developer over the analysis period to cover all ownership costs, after taxes, at the developer's discount rate.

3. Determine the LCC of energy for the off-taker using the off-taker's discount rate, considering:

- Purchasing energy from the serving utilities and fuel suppliers

- Energy services payments the off-taker will make to the developer for procuring energy from the project

4. Calculate the NPV for the off-taker, considering payments to conventional utilities in the Base Case and the sum of conventional utility costs and energy services payments in the Alternative Energy Case. If the NPV is greater than zero, the project is considered economically viable for the off-taker and the developer is able to meet their profit requirements. 


\section{Description of Technologies}

A common set of characteristics define each technology REopt evaluates. These characteristics include capital, O\&M, and fuel costs as well as hourly capacity factors. The hourly capacity factor of a technology for a given time step is the percentage of rated output that can be obtained for that time step. For example, if a system has a rated capacity of $10 \mathrm{MW}$ but the hourly capacity factor for the given time step is only $10 \%$, the system would be expected to produce $1 \mathrm{MW}$ of power during that time step.

Dispatchable technologies are those that can adjust their power output on demand or be switched on and off via a control signal. Examples include biomass, WTE, LFG, conventional generators, energy storage, and the utility grid. These technologies are both sized and dispatched by the solver for maximum economic benefit. The hourly capacity factors for these technologies are based on the availability of the system, including both planned and unplanned maintenance. These technologies can be dispatched at partial loads so long as the minimum turndown ratio is upheld. Furthermore, technology ramp-rate restrictions (e.g. restrictions on the speed at which power output is changed over time) can be imposed if the ramping capability over a time step is more restrictive than the range of minimum and maximum rated power outputs.

Variable technologies are those that cannot be dispatched. Examples include solar PV, wind turbine generators, SWH, and SVP. The hourly capacity factors for these technologies are a function of the TMY time series resource data. The solver optimally sizes these technologies. In general, they are assumed to generate energy at a rate proportional to their hourly capacity factor, but their output is capable of curtailment when necessary.

Finally, energy conservation measures are also considered. Load reduction potential and its associated costs are simulated using building energy modeling tools and allowed to compete with energy-generation technologies as a part of the pool of candidate technologies REopt can select from. A specific energy conservation measure, GSHP, receives detailed treatment in the model.

The sections below provide a detailed description of how each technology is modeled. For each technology, resource and technical assumptions are preprocessed to define performance characteristics and costs, which are then passed as inputs to the optimization model.

\subsection{Variable Technologies}

\subsubsection{PV}

\section{Model Description}

REopt uses NREL's PVWatts application to determine the electricity production of installed solar PV systems. By default, REopt assumes fixed-tilt arrays oriented due south with a tilt angle equal to the latitude of the site location. All of the variables exposed via the PVWatts API are able to be modified within the REopt model. Other panel types 
and configurations are possible depending on client needs. Refer to the PVWatts technical reference manual for further modeling assumptions and descriptions (Dobos 2014).

The amount of electricity produced by the solar PV array at each time step is proportional to the hourly capacity factor at the site. Because the production of solar PV arrays tends to decline over their lifespan yet the model only optimizes over one year, we calculate an annual production profile that has an economic equivalent production profile with $0.5 \% /$ year degradation over the analysis period. This calculation is done by applying the ratio of geometric series present worth factor (with degradation included) and uniform series present worth factor to calculate the economic equivalent profile.

\section{Resource Data}

Hourly solar radiation data are based on TMY2 measurements from the $1991-2005$ National Solar Radiation Database (Wilcox 2007). Alternatively, TMY3 can be used. Site location is mapped to the closest available station. If hourly solar radiation data is not available for the site under consideration in the TMY2 or TMY3 data sets (e.g. certain international locations), it is possible to use custom input files in the TMY format.

\section{Assumptions}

The size of the solar PV installation is limited by available roof or land space. The default assumption allows $1 \mathrm{MW}$-DC of solar PV to be installed for every 6 acres of land available. This takes into account row spacing for shading and other installation factors. For roof area, the default assumption is $1 \mathrm{~kW}$-DC for every $100 \mathrm{ft}^{2}$ of available roof space.

A solar PV array is expected to last 25 years with periodic maintenance. The associated inverter is likely to need replacement once during that time; the replacement cost is amortized into the annual maintenance costs. Table 7 summarizes main technology assumptions (based on PVWatts defaults) and data sources for solar PV modeling in REopt.

Table 7. PV - Main Technology Data Sources and Assumptions

\begin{tabular}{ll}
\hline Resource Data Source & TMY2 \\
\hline System Losses & $14 \%$ (soiling, electrical wiring losses, availability) \\
\hline Inverter Efficiency & $96 \%$ \\
\hline Annual Performance Degradation & $0.5 \%$ \\
\hline Space Requirements & $6 \mathrm{acres}^{2} \mathrm{MW}-\mathrm{DC}$ (ground-mount) \\
& $100 \mathrm{ft}^{2} / \mathrm{kW}$-DC (rooftop) \\
\hline Useful Life & 25 years \\
\hline Tracking & Fixed at tilt equal latitude \\
\hline Capital and O\&M Costs & See Appendix A \\
\hline
\end{tabular}




\subsubsection{Wind}

\section{Model Description}

REopt models wind turbines of five different sizes in three categories: small $(10 \mathrm{~kW})$, medium $(100 \mathrm{~kW})$, and utility scale $(>1 \mathrm{MW})$. Characteristics are listed in Table 8 . The class for large wind turbines is selected based on the average annual wind speed at the site location as determined by TMY wind resource data. Speed classifications are set by the International Electrotechnical Commission (IEC).

Table 8. Specifications of Modeled Wind Turbines

\begin{tabular}{c|c|c|ccc}
\hline Size & Small & Medium & \multicolumn{3}{c}{ Large } \\
\hline Nameplate & $10 \mathrm{~kW}$ & $100 \mathrm{~kW}$ & $3000 \mathrm{~kW}$ & $2000 \mathrm{~kW}$ & $1800 \mathrm{~kW}$ \\
IEC Class & & & Class 1 & Class 2 & Class 3 \\
(Average Wind Velocity) & & - & $(v>9 \mathrm{~m} / \mathrm{s})$ & $(7.5 \mathrm{~m} / \mathrm{s}<v<9 \mathrm{~m} / \mathrm{s})$ & $(v<7.5 \mathrm{~m} / \mathrm{s})$ \\
Power Control Method & Stall & Stall & Pitch & Pitch & Pitch \\
Nacelle Height & $30 \mathrm{~m}$ & $50 \mathrm{~m}$ & $80 \mathrm{~m}$ & $80 \mathrm{~m}$ & $80 \mathrm{~m}$ \\
\hline
\end{tabular}

Power curves for each machine are selected from commercially available units, but the models selected are intended to show the representative performance of a wind turbine of a given size and class and not as an endorsement for a particular machine or manufacturer. Therefore, the make and power curves for the representative turbines chosen are not included in this report.

To calculate the energy output of a wind turbine at each time step, turbine-specific power curves are used. TMY velocities are matched to velocities in the turbine power array, which then correspond to different power outputs. Velocities that fall in between values on the power curve are interpolated.

For nacelle heights that do not match the heights of the TMY data, wind velocity at the turbine nacelle, $V_{\text {nacelle }}$, is calculated by adjusting for wind shear, $\tau$, using the two TMY wind speeds and heights closest to the nacelle height:

$$
V_{\text {nacelle }}=V_{\mathrm{TMY}}\left(\frac{H_{\text {nacelle }}}{H_{\mathrm{TMY}}}\right)^{\tau}
$$

where

$$
\tau=\frac{\log \left(V_{\mathrm{TMY} 1} / V_{\mathrm{TMY} 2}\right)}{\log \left(H_{\mathrm{TMY} 1} / H_{\mathrm{TMY} 2}\right)}
$$


If the turbine nacelle height is below $50 \mathrm{~m}$, the lowest height for data in the TMY file, hours with negative shear values are assumed to have shear values of 0.1 . That is, wind speed is assumed to not increase at heights below $50 \mathrm{~m}$. Otherwise, projecting wind speed below $50 \mathrm{~m}$ with negative shear results in unreasonably high wind speeds near ground level. This rule assumes that during hours when $V_{50 m}>V_{80 m}$, the maximum wind speed in the wind speed profile occurs at $50 \mathrm{~m}$, not below.

Because power output in the manufacturer's performance data assumes air density at standard conditions, an air density correction factor to account for the actual air density of the TMY resource is applied to obtain predicted power outputs. Correction methods vary depending on whether the turbine regulates power using pitch or stall control.

\section{Stall control}

Air density correction for stall-controlled turbines is applied as follows:

$$
P_{\text {corrected }}=P\left(\frac{\rho_{\text {actual }}}{\rho_{\text {STP }}}\right)
$$

where $P_{\text {corrected }}$ is the corrected power output of the wind turbine, $P$ is the direct power output from the turbine performance array, $\rho_{\text {actual }}$ is the actual air density measured in the TMY data, and $\rho_{\text {STP }}$ is the air density at standard temperature and pressure $\left(\rho_{\mathrm{STP}}=1.225 \mathrm{~kg} / \mathrm{m}^{3}\right)$.

$\rho_{\text {actual }}$ is linearly interpolated using the density and height values closest to the nacelle height for nacelle heights that do not directly match TMY data heights.

\section{Pitch control}

For pitch-controlled turbines, air density correction is done by calculating an effective velocity:

$$
V_{\text {effective }}=V_{\text {actual }}\left(\frac{\rho_{\text {actual }}}{\rho_{\text {STP }}}\right)^{0.3333}
$$

The new velocity, $V_{\text {effective }}$, is used in the turbine power array lookup to determine $P_{\text {corrected }}$.

REopt assumes $15 \%$ losses to account for wake effects, electrical losses, limited availability, and turbine performance degradation. 


\section{Resource Data}

REopt uses wind resource data provided by AWS Truepower. Data coverage extends over the entire continental United States with some exclusion areas where data are not available. These areas are primarily confined to national parks and densely populated urban locations. Currently, REopt assesses only land-based wind potential. Two main data sets are considered:

- Gross Capacity Factor (GCF). Annual gross capacity factors are provided for each $200 \mathrm{~m}$ by $200 \mathrm{~m}$ area across the lower 48 states. GCFs are estimated by AWS Truepower assuming a 1.5 MW GE wind turbine with a nacelle height of $80 \mathrm{~m}$.

- Hourly TMY data. Values for wind speed, wind direction, air density, and temperature at heights of $30 \mathrm{~m}, 50 \mathrm{~m}, 80 \mathrm{~m}, 110 \mathrm{~m}$, and $140 \mathrm{~m}$ above ground level are provided. The data set includes over 21,619 TMY files, with at least one for each $20 \mathrm{~km}$ by $20 \mathrm{~km}$ region. These regions are further subdivided into bins of $3 \%$ increments for each height above ground if the GCF varies by more than a $3 \%$ range within the region.

REopt queries the wind resource database using a site's latitude and longitude, and a desired search radius. The following procedure is followed to obtain the TMY file specifying the available wind resource at a particular site:

1. All GCFs within the specified search radius are collected.

2. The distribution of GCFs within the set is calculated, and the GCF value that represents the $75^{\text {th }}$ percentile of the distribution is determined.

3. The TMY data set is searched to locate TMY data closest to the site location with the same GCF as determined in Step 2. Bins within the $20 \mathrm{~km}$ x $20 \mathrm{~km}$ region associated with the latitude and longitude provided are first searched. If no matching GCF is found, the search space expands radially outward to the next $20 \mathrm{~km} \mathrm{x} 20 \mathrm{~km}$ region to the east. A ring of outward regions are searched in a clockwise fashion until a TMY file with a matching GCF is found or until the search space exceeds the specified search radius.

Although the model uses a database of wind resources that is representative of the regional wind availability near the client site, wind resource is highly sensitive to site-specific features and should be verified as part of the project development due diligence before any investment decisions are made. International sites require more detailed analysis of their potential wind resource as the AWS Truepower data set does not contain data on most of these locations. A custom wind resource file can be input into the model, yet this requires generation of this file based on local measurements or nearby meteorological station data.

\section{Assumptions}

Wind projects are constrained by land availability whenever this information is provided. 
Otherwise, REopt assumes availability and allows $1 \mathrm{MW}$ of wind to be installed for every 30 acres of space for wind projects above $1.5 \mathrm{MW}$ (the typical range for wind space constraints is 1-82 acres/MW). The main technology data sources and assumptions are summarized in Table 9.

Table 9. Wind - Main Technology Data Sources and Assumptions

\begin{tabular}{ll}
\hline Resource Data Source & AWS Truepower \\
\hline System Losses & $\begin{array}{l}15 \% \text { (wake effects, electrical losses, limited availabil- } \\
\text { ity, turbine performance degradation) }\end{array}$ \\
\hline $\begin{array}{l}\text { Default Search Radius for } \\
\text { Resource Availability }\end{array}$ & 1 mile \\
\hline Space Requirements & 30 acres / MW for turbine sizes above 1.5 MW \\
\hline Capital and O\&M Costs & See Appendix A \\
\hline
\end{tabular}

\subsubsection{Solar Water Heating}

\section{Model Description}

REopt models an active closed-loop SWH system with indirect circulation and intraday storage capabilities. The system is comprised of a glazed flat-plate collector and a heat transfer fluid circulating pump. SWH can replace either conventional gas, propane, or electric water heating. The energy the new SWH system can displace is limited by the domestic hot water (DHW) load.

REopt models intra-day storage by creating a synthetic DHW load profile that reshapes daily hot water consumption to align with the solar irradiance profile. This allows SWH thermal energy to be used at different time periods within a day without explicitly modeling a storage tank. However, water heated on a given day must still be consumed within that day. Tank losses are ignored.

To create the synthetic DHW load profile, hourly DHW energy consumption is summed over the course of each day and then redistributed as follows:

$$
\operatorname{DHW}_{n_{t}}=\operatorname{DHW}_{\operatorname{day}_{n}}\left(\frac{\Phi_{n_{t}}}{\Phi_{\mathrm{day}_{n}}}\right)
$$

where $\mathrm{DHW}_{n_{t}}$ is the domestic hot water consumption at time step $t$ on day $n, \mathrm{DHW}_{\text {day }_{n}}$ is the total hot water consumption over day $n, \Phi_{n_{t}}$ is the total solar irradiance at time step $t$ on day $n$, and $\Phi_{\text {day }_{n}}$ is the sum of the total solar irradiance over day $n$. Total solar irradiance includes direct, diffuse, and ground-reflected radiation. 
The synthetic DHW load profile has the same shape as the solar generation profile, but scaled so that the area under the curve corresponds to a single day's water heating energy demand.

REopt then sizes the SWH system by first converting the water heating energy demand in kilowatt-hours to a required gallons-per-day metric using the fact that $1 \mathrm{Btu}$ of energy is needed to raise the temperature of 1 pound of water by 1 degree Fahrenheit:

$$
\mathrm{DHW}_{\text {gallons }_{n}}=\frac{\mathrm{DHW}_{\mathrm{kWh}} \cdot \eta_{\text {existing }} \cdot \frac{3413 \mathrm{BTU}}{\mathrm{kWh}}}{\left(T_{\mathrm{set}}-T_{\text {main }}\right) \cdot \frac{8.34 \text { pounds }}{\text { gallon }}}
$$

$\mathrm{DHW}_{\text {gallons }_{n}}$ is the total number of gallons of water to be heated on day $n, \mathrm{DHW}_{\mathrm{kWh}_{n}}$ is the total energy expended in kWh to heat DHW on day $n, \eta_{\text {existing }}$ is the efficiency of the existing water heating system, $T_{\text {set }}$ is the assumed hot water delivery temperature, and $T_{\text {main }}$ is the average temperature of the water delivered before any heating is done by the SWH system.

A calculated gallons per day metric is used to inform SWH efficiency, which is inversely proportional to the solar fraction the system achieves. As system size increases, solar fraction increases and efficiency declines. A collector-to-load ratio is defined as the ratio of collector area to DHW demand with units of $\mathrm{ft}^{2} /$ gallon/day. A constant efficiency is modeled for three ranges of collector-to-load ratios in REopt (see Table 10).

Table 10. Efficiencies for Different SWH System Sizes

\begin{tabular}{ccc}
\hline System Size & Collector-to-Load Ratio & Efficiency \\
\hline Small & $<0.1$ & $60 \%$ \\
Medium & $0.1-0.2$ & $45 \%$ \\
Large & $>0.2$ & $30 \%$ \\
\hline
\end{tabular}

The final power production achieved at each time step, $\mathrm{P}_{t}$, by the $\mathrm{SWH}$ system is given by the following equations.

If the exisiting DHW system is thermal:

$$
\mathrm{P}_{t}=\Phi_{t} \cdot \frac{\eta_{\mathrm{SWH}}}{\eta_{\text {existing }}}
$$

where $\Phi_{t}$ is the solar irradiance at time step $t, \eta_{\mathrm{SWH}}$ is the efficiency of the SWH system from Table 10, and $\eta_{\text {existing }}$ is the efficiency of the existing water heating system. 
If the existing DHW system is electric:

$$
\mathrm{P}_{t}=\left(1-\mathrm{P}_{\text {pump }}\right) \cdot \Phi_{t} \cdot \frac{\eta_{\mathrm{SWH}}}{\eta_{\text {existing }}}
$$

where $\mathrm{P}_{\text {pump }}$ is the percentage of power needed to operate the SWH pump.

Energy incurred to run the SWH system is added to the site load. Modeled as $2 \%$ of the energy saved by the SWH system, this operating penalty is added to total site consumption if the optimization chooses to install a SWH system.

\section{Resource Data}

The SWH model uses solar resource data including direct normal radiation, diffuse radiation, and ground-reflected radiation obtained from the TMY3 geospatial data set. Site location is mapped to the closest measurement station across 1,020 locations in the continental United States.

DHW demand is obtained from EnergyPlus simulations of the closest matching building type out of 16 different DOE commercial reference buildings set in the appropriate climate zone.

\section{Assumptions}

The main SWH technology assumptions are summarized in Table 11. Temperature set points and efficiencies are fixed at the specified values for all locations unless alternative client input is provided.

Table 11. SWH - Main Technology Data Sources and Assumptions

\begin{tabular}{ll}
\hline Resource Data Source & TMY3 \\
\hline Pump Power & $2 \%$ of energy saved by the SWH system \\
\hline Average Water Main Temperature & $20^{\circ} \mathrm{F}$ \\
\hline Hot Water Delivery Temperature & $130^{\circ} \mathrm{F}$ \\
\hline Existing DHW System Efficiency & $90 \%$ \\
\hline SWH System Efficiency & See Table 10 \\
\hline Capital and O\&M Costs & See Appendix A \\
\hline
\end{tabular}




\subsubsection{Solar Ventilation Air Preheating}

\section{Model Description}

REopt models the SVP system as a transpired solar collector on the south-facing wall of a building coupled with a circulating fan that draws air into the outside air intake of a building's heating, venting, and air-conditioning system. The preheated air produced by such a system reduces the heating costs associated with the existing electrical or thermal space heating scheme. The quantity of preheated air produced, and therefore the fuel saved, is limited by the outside air heating load, and system size is constrained by the area available on the south-facing wall of the building.

To model the SVP system, REopt first calculates the minimum ventilation rate required for acceptable indoor air quality per ASHRAE Standard 62.1-2007 specifications (Stanke et al. 2007). The total ventilation rate can be broken down into the fixed ventilation required on a per-square-footage basis and the variable ventilation required depending on occupancy per square feet. Total ventilation, $\mathrm{V}_{\mathrm{SVP}}$, in cubic feet per minute (CFM) is then found as follows:

$$
\mathrm{V}_{\mathrm{SVP}}=\left(\mathrm{V}_{\mathrm{sqft}}+\mathrm{V}_{\mathrm{person}}\right) \cdot \mathrm{A}_{\mathrm{sqft}}
$$

where $A_{\text {sqft }}$ is the total square footage of the building under consideration. Both $\mathrm{V}_{\text {sqft }}$ and $\mathrm{V}_{\text {person }}$ have units of $\mathrm{CFM} / \mathrm{ft}^{2}$ with typically assumed values shown in Table 13 . Building square footage is a user-specified input.

The total wall area available for an SVP installation, $\mathrm{A}_{\mathrm{SVP}}$, is then calculated:

$$
\mathrm{A}_{\mathrm{SVP}}=\left(\mathrm{L}_{\text {height }} \cdot \mathrm{A}_{\mathrm{sqft}}\right) / \mathrm{L}_{\text {depth }}
$$

where $\mathrm{A}_{\text {sqft }}$ is the square footage of the building, $\mathrm{L}_{\text {height }}$ is the building height, and $\mathrm{L}_{\text {depth }}$ is the building depth. Typically assumed values for building height and depth are also found in Table 13.

Table 12. SVP System Efficiency

\begin{tabular}{ccc}
\hline System Size & Efficiency & $\begin{array}{c}\text { Ventilation Rate } \\
{\left[\mathrm{ft}^{2} / \mathrm{CFM}\right]}\end{array}$ \\
\hline Small & $60 \%$ & 0.3125 \\
Medium & $40 \%$ & 0.5625 \\
Large & $40 \%$ & 0.5625 \\
\hline
\end{tabular}


The required ventilation rate and the wall area available both constrain SVP sizing. Like SWH systems, SVP efficiency is also inversely proportional to system size. In other words, as the fraction of preheated ventilation air increases for a given space-heating load, system efficiency decreases. Table 12 shows how REopt models the efficiency decline as system size increases. Once system size is selected, a constant SVP efficiency is applied to each time step of the simulation.

To determine the final thermal production achieved by an SVP system at each time step, t, REopt uses monthly SVP resource data (National Renewable Energy Laboratory 1998) and higher-granularity TMY solar radiation measurements to create a time series production profile:

$$
\mathrm{P}_{t}=\Phi_{\mathrm{SVP}_{m}} \cdot \frac{\Phi_{\mathrm{DNI}_{t}}}{\Phi_{\mathrm{DNI}_{m}}} \cdot \frac{\eta_{\mathrm{SVP}}}{\eta_{\text {existing }}}
$$

where $\mathrm{P}_{t}$ is the final power production at time step $t, \Phi_{\mathrm{SVP}_{m}}$ is the monthly SVP production data, $\Phi_{\mathrm{DNI}_{t}}$ is the direct normal solar irradiance at time step $t, \Phi_{\mathrm{DNI}_{m}}$ is the total monthly direct normal solar irradiance, $\eta_{\mathrm{SVP}}$ is the efficiency of the SVP system from Table 12, and $\eta_{\text {existing }}$ is the efficiency of the existing space-heating system.

Energy incurred to run the SVP system is added to the site load. This includes the fan power required to circulate the preheated air. Modeled as $2 \%$ of the energy saved by the SVP system, this operating penalty is added to total site consumption if the optimization chooses to install an SVP system.

\section{Resource Data}

The heat production of the modeled SVP system is based on monthly SVP resource data and the TMY3 geospatial data set that considers ambient temperature and solar insolation.

\section{Assumptions}

The main SVP technology assumptions are summarized in Table 13. Ventilation rates and average building dimensions are assumed to be constant across site locations and scenarios unless otherwise specified by the client. 
Table 13. SVP - Main Technology Data Sources and Assumptions

\begin{tabular}{ll}
\hline Resource Data Source & Internal NREL modeling, TMY3 \\
\hline Ventilation Rate per Square Footage & $0.06 \mathrm{CFM} / \mathrm{ft}^{2}$ \\
\hline Ventilation Rate per Person per Square Feet & $0.042 \mathrm{CFM} / \mathrm{ft}^{2}$ \\
\hline Average Building Height & $18 \mathrm{ft}$ \\
\hline Average Building Depth & $200 \mathrm{ft}$ \\
\hline Pump Power & $2 \%$ of energy saved by the SVP system \\
\hline Current Space Heating System Efficiency & $90 \%$ \\
\hline SVP System Efficiency & See Table 12 \\
\hline Capital and O\&M Costs & See Appendix A \\
\hline
\end{tabular}

\subsection{Dispatchable Technologies}

\subsubsection{Utility Grid}

REopt models the utility grid as an ideal source capable of supplying an unlimited amount of electricity and thermal fuel. Because it already exists, the model does not incur any capital or O\&M costs for using the grid. Energy from the grid incurs only the costs specified by the relevant utility rate tariff.

The costs to acquire electricity from the grid are divided into usage costs $(\$ / \mathrm{kWh})$ and demand charges $(\$ / \mathrm{kW})$. The model pays for each $\mathrm{kWh}$ of electricity consumed at a rate specified by the utility tariff, whereas demand charges are accrued based on the largest grid purchase within specific hours of particular demand ratchets. The model can accommodate any number of demand ratchets throughout the year. Common examples include peak and off-peak demand periods each day, with the hours associated with each period changing seasonally.

For microgrid analyses, the utility grid can be disabled.

\subsubsection{Generators}

\section{Types Modeled}

Five electrical and thermal generator technologies are modeled in REopt. The inputs to these technology models are then modified to reflect the different efficiencies and heating values for the various fuel types. The five technologies are described here, and then details 
regarding the different fuel resources (including biomass, landfill gas, municipal solid waste incineration, and conventional fuels) and associated efficiencies are outlined in the following subsections.

The five technologies are listed below:

1. Condensing steam turbine. This system generates electricity in a steam cycle. Steam is generated in a boiler and passed through a fully condensing turbine. It achieves a high electrical efficiency by fully condensing the steam (down to approximately 2 pounds per square inch actual). Plant parasitics are reflected in a derate on the plant electrical efficiency.

2. Backpressure steam turbine (type CHP). This system generates heat and electricity in a steam cycle by feeding steam generated in a boiler through a turbine to generate electricity. This system provides a fixed ratio of electric to thermal energy output. There is no cooling tower associated with this system, so the site must have sufficient thermal load to use the heat. This system has a lower capital cost than the alternate CHP option (next), and a lower electrical efficiency.

3. Condensing turbine with steam bypass (type CHP). This system models a boiler and a fully condensing steam turbine (as in the electric-only case), but can vary the ratio of electric to thermal energy output by diverting steam through a bypass valve. This system requires a cooling tower to dump waste heat when producing only electricity. Plant parasitics are reflected in a derate of the electrical efficiency and deaerator thermal requirements are reflected in a derate of the thermal efficiency.

4. Combustion steam boiler. This system generates thermal energy only through the combustion of fuel. Deaerator thermal requirements are reflected in a derate of the thermal efficiency.

5. Reciprocating engine. The reciprocating engine consumes fuel and generates electricity. The fuel consumption of these generators is modeled using a linear fuel curve with a nonzero y-intercept (which allows for nonlinear generator efficiencies) based on data provided by the manufacturer. The model can account for ambient temperature impacts on available capacity by preprocessing hourly temperature data from the TMY file through a manufacturer curve. Conventional generators are not modeled with a waste heat recovery system (except in custom configurations for detailed analysis). Generators can be specified to only operate during grid outages.

For configurations 1 through 4 discussed earlier, a steam boiler is included. The boiler fuel supply depends on resource availability and could include biomass, landfill gas, municipal solid waste, and conventional fossil fuels. The general approach for modeling the steambased technologies (configurations $1-4$ ) is to calculate a heat rate for each technology. This heat rate calculation is done by assigning values to each element in this chain: fuel high heating value $\rightarrow$ boiler efficiency $\rightarrow$ electrical and/or thermal efficiency. It also allows users to track the fuel consumed per unit of energy generated (both thermal and electric). 
For the reciprocating engine model, heat rate is already represented in the fuel curve.

Each generator system is assumed to have a minimum turndown ratio, meaning that it can operate at partial loading down to a given fraction of its nameplate capacity; any lower and it must shut off. The systems are also assumed to have a certain availability (representing both planned and unplanned outages) that is input to the model as a percent of hours available.

\subsubsection{Biomass}

The model includes four configurations of biomass systems (types $1-4$ mentioned earlier), each of which is modeled as a mass-burn boiler. The feedstock is directly burned with air to produce steam, which can then be used to generate both heat and power.

The cost of obtaining the feedstock includes a purchase price and delivery cost, which depend on the distance between the site and location where biomass is collected. Distances are grouped into three rings with different associated costs as listed in Table 14. The cost function reaches a maximum at a distance greater than 50 miles. The estimated price includes the cost to acquire the material at the source as well as the cost to transport it to the site. Costs are based on biomass market price estimates from biomass industry journals. Biomass systems consume the cheapest fuel first from the nearest resource sites.

Table 14. Biomass Fuel Costs

\begin{tabular}{cc}
\hline Bin & Cost $(\$ /$ ton $)$ \\
\hline Onsite & $\$ 0$ \\
25-mile radius & $\$ 20.50$ \\
50-mile radius & $\$ 32.50$ \\
$>50$-mile radius & $\$ 80.00$ \\
\hline
\end{tabular}

\section{Resource Data}

Three types of biomass resource availability (dry tonnes/year) are programmatically queried from the geospatial database: forest residues, primary mill residues, and secondary mill residues. At distances greater than 50 miles, the resource is considered unconstrained; however, costs for delivery increase sharply. Crop residues are available from the database but are not considered because there is no system in place to effectively collect and process this feedstock:

1. Forest Residues. Forest residues are logging residues and other removable material left after performing silviculture operations and site conversions. For example, these include leftover portions of trees that are cut or killed during logging operations. 
Resource data are obtained from the U.S. Department of Agriculture (USDA) Forest Service's Timber Products Output database (USDA Forest Service 2007).

2. Primary Mill Residues. Primary mill residues include the wood material (coarse and fine) and bark generated at manufacturing plants (primary wood-using mills) when round wood products are processed into primary wood products such as slabs, edgings, trimmings, sawdust, veneer clippings and cores, and pulp screenings. Resource data are also obtained from USDA Forest Service's Timber Products Output database (USDA Forest Service 2007).

3. Secondary Mill Residues. Secondary mill residues include wood scraps and sawdust from woodworking shops, furniture factories, wood container and pallet mills, and wholesale lumberyards. Resource data are obtained from the U.S. Census Bureau's County Business Patterns database (U.S. Census Bureau 2002).

\section{Assumptions}

The default efficiencies, availabilities, and minimum turndowns are shown for the four biomass technology configurations in Table 15.

Table 15. Biomass Technology Assumptions

\begin{tabular}{r|c|c|c|c}
\hline & Electric & CHP Backpressure & CHP Condensing & Thermal \\
\hline Electric Efficiency & $23 \%$ & $13 \%$ & $23 \%$ & $\mathrm{~N} / \mathrm{A}$ \\
\hline Thermal Efficiency & $\mathrm{N} / \mathrm{A}$ & $73 \%$ & $91 \%$ & $91 \%$ \\
\hline Availability & $85 \%$ \\
\hline Boiler Efficiency & $80 \%$ \\
\hline Minimum Turndown ratio & \multicolumn{3}{|c}{$40 \%$} \\
\hline Fuel Heat Content & 9.2 MMBtu/ton \\
\hline Capital and O\&M Costs & See Appendix A \\
\hline
\end{tabular}

\subsubsection{Landfill Gas}

LFG systems use methane gas generated by the anaerobic decomposition of carbon-based waste deposited in a local landfill. In REopt, LFG systems are assumed to generate either only electricity or only steam for heating. The landfill gas module utilizes the reciprocating engine technology model and the boiler model. 


\section{Resource Data}

REopt leverages data from the Environmental Protection Agency's Landfill Methane Outreach Program (LMOP) to determine: (1) the viability of a landfill for methane production, and (2) the maximum generation capacity of the landfill. The LMOP uses a first-order decay model to estimate the gas production of a landfill based on the dates of operation, quantity of waste in place, and the fill rate. It is assumed that the methane generated from a candidate landfill will be piped to the site for use in either electricity generation or a boiler. Therefore, for a site to access the landfill gas, a pipeline must be constructed, the cost of which is factored into the model. The LMOP data has been integrated into the geospatial database, and for each site the database returns the distance to the closest viable landfill along with its maximum generation capacity. Only landfills within a 15-mile radius are considered viable in the model.

It is also assumed that a minimal cost must be paid to the landfill for usage of the gas, this is modeled at $\$ 1 /$ MMBtu (based on communication with an LMOP contractor).

\section{Assumptions}

The default assumptions for efficiencies, availabilities, and minimum turndowns are shown for the two LFG technology configurations in Table 16.

Table 16. Landfill Gas Technology Assumptions

\begin{tabular}{r|c|c}
\hline & Electric & Thermal \\
\hline Electric Efficiency & $33 \%$ & $\mathrm{~N} / \mathrm{A}$ \\
\hline Thermal Efficiency & $\mathrm{N} / \mathrm{A}$ & $80 \%$ \\
\hline Boiler Efficiency & $\mathrm{N} / \mathrm{A}$ & $80 \%$ \\
\hline Availability & $85 \%$ \\
\hline Minimum Turndown ratio & $30 \%$ \\
\hline Fuel Heat Content & $10.6 \mathrm{MMTBU} /$ ton \\
\hline Maximum Search Radius & 15 miles \\
\hline Capital and O\&M Costs & See Appendix A \\
\hline
\end{tabular}

\subsubsection{Waste to Energy}

WTE technologies generate energy through incineration of MSW. Although there are several technologies for converting MSW to energy, REopt only considers the most common: mass burn. Mass burn directly combusts MSW as a fuel with minimal processing. 
The WTE module contains the same four configurations as the biomass module and has similar turndown requirements. The primary difference between these models is the boiler and turbine efficiencies as well as the capital costs to build the systems. System efficiencies are different due to the lower operating pressures of WTE systems to minimize corrosion resulting from the chlorides released during combustion.

\section{Resource Data}

The MSW within a given area is calculated by multiplying the population within that area by the per capita waste generation. Although the procurement of a contract diverting MSW to a WTE plant can be difficult to obtain, the client is assumed to be able to obtain the calculated waste available during the prescreening process. WTE facilities are paid to accept MSW, adding a source of revenue referred to as the tipping fee. The tipping fee is estimated based on published data and varies from $\$ 25-\$ 85$ per ton with an average of $\$ 44 /$ ton (Haaren, Themelis, and Goldstein 2010). It is assumed that the site will obtain a fee equal to that of a local landfill.

\section{Assumptions}

The default assumptions for efficiencies, availabilities, and minimum turndowns are shown for the four WTE technology configurations in Table 17.

Table 17. WTE Technology Assumptions

\begin{tabular}{r|c|c|c|c}
\hline & Electric & CHP Backpressure & CHP Condensing & Thermal \\
\hline Electric Efficiency & $21 \%$ & $11 \%$ & $21 \%$ & $\mathrm{~N} / \mathrm{A}$ \\
\hline Thermal Efficiency & $\mathrm{N} / \mathrm{A}$ & $73 \%$ & $91 \%$ & $91 \%$ \\
\hline Availability & \multicolumn{3}{|c}{$85 \%$} \\
\hline Boiler Efficiency & $75 \%$ \\
\hline Minimum Turndown ratio & $40 \%$ \\
\hline Fuel Heat Content & \multicolumn{5}{|c}{10.4 MMBtu/ton } \\
\hline Capital and O\&M Costs & See Appendix A \\
\hline
\end{tabular}

\subsubsection{Conventional Generators}

Conventional generators use the reciprocating engine model, and generally depend on the user to input manufacturer data to capture generator performance. Fuel consumption as a function of power output is processed into a linear equation $(y=m x+b)$, and the slope and $y$-intercept of the curve are entered as inputs. Available fuel quantities and costs are 
also entered into the model. As long as the units for the fuel quantities, costs, and linear equation are all consistent, any unit (e.g., gallons or MMBtu) may be used in the model.

\section{Assumptions}

Conventional generator technologies are generally used to model existing assets during the detailed characterization of a site. If a generator is being considered for a new application, generic fuel consumption versus load profiles are utilized to generate a normalized fuel consumption linear equation. Example fuel curves are shown in Figure 3.

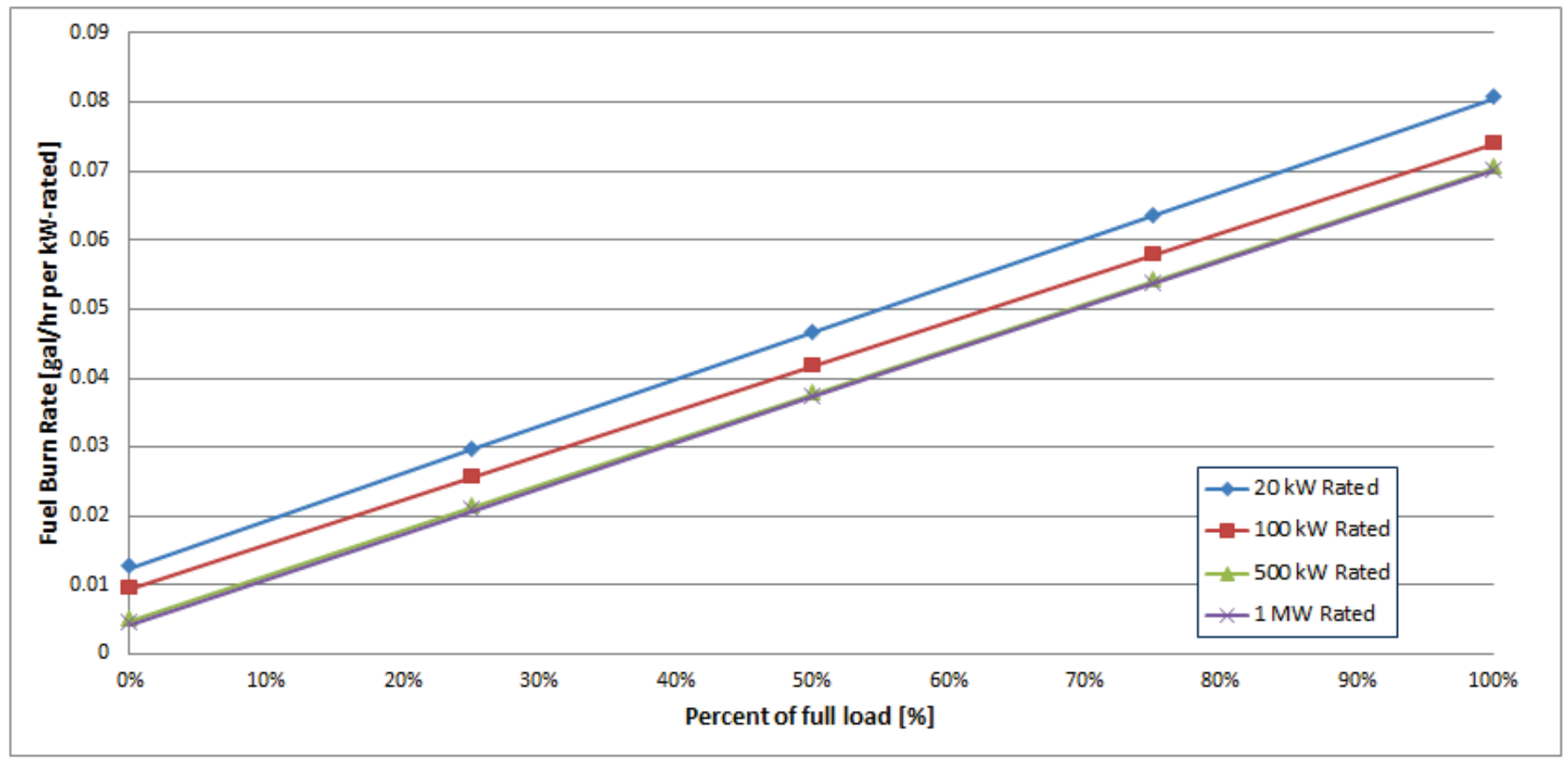

Figure 3. Example fuel burn rate curves for diesel generators

\subsubsection{Energy Storage Technologies}

\section{Model Description}

Energy storage, including batteries, thermal storage, and water storage, is modeled as a "reservoir" in REopt, wherein energy produced during one time step can be consumed during another. REopt does not explicitly model battery chemistries, but rather imposes heuristic constraints that are designed to ensure the battery operates within the manufacturer's specifications. A round-trip efficiency is assumed and limits are imposed on the minimum state of charge, charging and discharging rates, and the number of cycles per day. The model is able to select and size both the capacity of the battery in $\mathrm{kWh}$ and the power delivery in $\mathrm{kW}$. By default, any technology can charge the energy storage device, but charging can also be limited to specific technologies.

Energy storage technologies are modeled to capture revenue from multiple value streams: performing energy arbitrage, time-shifting excess renewable energy production, selling 
ancillary services to the grid, participating in demand response programs, deferring transmission and distribution upgrades, reducing demand charges or "peak shaving," and increasing the energy resiliency of a site.

\section{Assumptions}

The following characteristics can be set to define the battery energy storage model in REopt:

- Minimum state of charge (SoC). A minimum SoC for the device may be specified, typically as a percentage of the device capacity.

- Charge/discharge rate. REopt provides several options for specifying the maximum charge/discharge rate of a device. The maximum charge / discharge rate may be specified as an E-rate: the maximum power the device can provide over a specific period of time. A device with a capacity of $100 \mathrm{kWh}$ and an E-rate of 1 can provide $100 \mathrm{~kW}$ for 1 hour. The same device with an E-rate of 2 could provide $200 \mathrm{~kW}$ for half an hour. Thus, by enforcing a specified E-rate, REopt limits the charge/discharge rate of a device based on its size.

For some energy storage systems, the charge/discharge rate may be constrained by the capacity of the associated power electronics (inverter/rectifier). In these cases, REopt uses a cost function to determine the optimum inverter/rectifier sizing independent of the storage device. REopt then provides the cost-optimal storage size as well as the cost-optimal inverter/rectifier size in which the charge/discharge rate of the storage device is limited by the associated power electronics. An absolute limit on the charge/discharge rate can also be specified if the capacity of the inverter/rectifier is already known.

REopt also has the capability to limit the discharge rate based on the SoC of the device. As the SoC decreases, the maximum discharge rate decreases.

- Efficiencies. Efficiencies of the power electronics can be specified along with the round-trip efficiency of the energy storage device. For example, a system may have an inverter efficiency of $85 \%$, a rectifier efficiency of $80 \%$, and a round-trip storage efficiency of $80 \%$; the resulting efficiency of the round-trip path from the AC grid to the DC battery then back to the AC load would then be $54.4 \%$. Depending on the configuration of the system, some technologies (such as solar PV) may be able to charge the battery directly, thereby avoiding efficiency losses from the inverter.

- Initial/final SoC. The user can specify the initial/final SoC of the device, which is useful for bench marking the performance of one configuration against another.

- Energy storage operating/replacement costs. REopt can assess the cost per kWh of energy transferred through the device, allowing for an amortized replacement cost of the battery. 
- Useful life. The life expectancy of a battery is typically assumed to be 10 years; as a result, amortized replacement costs can be included in the model. A battery may not last the entire 10 years, however, especially if it experiences an excessive number of deep charge/discharge cycles. Although degradation as a result of cycling can be included in the optimization model, it increases computational complexity. Therefore, REopt typically assumes a useful battery life of 10 years, based on calendar degradation; the dispatch is then postprocessed using the rain-flow algorithm (Safari and Delacourt 2011, Downing and Socie 1982) to verify the assumption.

Table 18 shows the default values assumed for key battery characteristics.

Table 18. Typical Characteristics of a Lithium-ion Battery Model

\begin{tabular}{lc}
\hline Battery Characteristics & \\
\hline Composite AC-AC Round-Trip Efficiency & $82.9 \%$ \\
Battery Round-Trip Efficiency & $90 \%$ \\
Inverter Efficiency & $96 \%$ \\
Rectifier Efficiency & $96 \%$ \\
Minimum Charge & $20 \%$ \\
Initial SoC & $50 \%$ \\
\hline Useful Life & 10 years \\
Capital and O\&M Costs & See Appendix A \\
\hline
\end{tabular}

\subsection{Energy Conservation Measures}

ECMs are simulated in a whole building energy modeling tool (OpenStudio) to obtain each ECM's production profile. This profile, which represents a reduction of the existing load, is then passed to REopt along with the installation cost, O\&M cost, and expected lifetime of the ECM. REopt can then select the cost-optimal combination of load-reducing ECMs and renewable energy generation.

ECMs may be modeled either individually or in combinations. If modeled individually, the interactions between ECMs are not modeled-each ECM is considered to be a stand-alone technology similar to a renewable energy technology. The optimal solution set may include some, none, or all of the ECMs as well as a mix of renewable energy technologies, grid purchases, and energy storage.

Alternatively, whole building energy modeling tools can be used to construct optimal combinations of ECMs at various price points. Each combination is a pareto-optimal set of ECMs that then competes as an ECM package against renewable energy candidates. 
REopt includes detailed modeling for one specific ECM, GSHP. This enables analysis of this technology without requiring an energy model to be run in order to calculate load reduction (or increase in the case of electrical heating load). This model leverages a TRNSYS model to establish technology performance and then REopt is able to optimally determine whether to install the technology or not. The following section describes the details regarding modeling of this ECM.

\subsubsection{Ground Source Heat Pumps}

\section{Model Description}

The GSHP model in REopt is based on the TRNSYS simulation software, originally developed at the University of Wisconsin-Madison (Klein 2017). The TRNSYS ground heat exchanger used in the REopt model is the TRNDST ground heat exchanger module (written by Daniel Pahud and Goran Hellstrom of University of Lund, Sweden). The model is used to size a vertical ground heat exchanger system based on a set of user-specified inputs.

The main inputs to the program include: hourly heating and cooling loads, ambient temperature, the coefficient of performance (COP) of the heat pump in both heating and cooling mode as a function of the heat-exchanger entering fluid temperature (EFT), and a set of technology parameters that define the GSHP system (see Table 19).

Using these inputs, the program executes the following sequence to determine the size of the pumps and ground heat exchanger system:

1. The annual peak heating load, peak cooling load, and peak combined load are determined from the input load profiles. The peak heating and the peak cooling loads are used to estimate initial sizes in the ground heat exchanger calculations. The peak combined load is used to set the required pump size.

2. Peak pump flow rate (gpm/ton) is calculated based on the user-specified nominal pump flow rate and the peak hourly combined load conditions. Peak pump power (W/gpm) is then calculated from the peak flow rate and the user-specified nominal pump power.

3. Using the value of the undisturbed ground as an initial estimate for the leaving fluid temperature from the ground heat exchanger, and hence the EFT to the heat pumps, the COP of the heat pumps in the heating and cooling mode are determined based on the provided relationship between heat pump performance and EFT.

Separate heating and cooling COPs are specified for a set range of EFTs: $-20^{\circ} \mathrm{F}$, $-10^{\circ} \mathrm{F}, 0^{\circ} \mathrm{F}, 10^{\circ} \mathrm{F}, 20^{\circ} \mathrm{F}, 30^{\circ} \mathrm{F}, 40^{\circ} \mathrm{F}, 50^{\circ} \mathrm{F}, 60^{\circ} \mathrm{F}, 70^{\circ} \mathrm{F}, 80^{\circ} \mathrm{F}, 90^{\circ} \mathrm{F}, 100^{\circ} \mathrm{F}, 110^{\circ} \mathrm{F}, 120^{\circ} \mathrm{F}$, $130^{\circ} \mathrm{F}, 140^{\circ} \mathrm{F}$, and $150^{\circ} \mathrm{F}$. The program linearly interpolates between the provided data points, but does not extrapolate beyond the limits of the range and instead uses the last provided value (e.g., an EFT of $-30^{\circ} \mathrm{F}$ will use the COP value at $-20^{\circ} \mathrm{F}$ ). 
The program assumes there are two heat pumps connected in parallel: one to meet the heating load and one to meet the cooling load. The program also assumes that all loads passed to it must be met (i.e., no hybrid systems to meet peak loads); if a hybrid system is to be considered, the loads passed to the TRNSYS model must be preprocessed to only contain the loads to be met by the GSHP system.

4. The power of the heat pump in heating mode at time step $t$ is calculated by dividing the heating load at time $t$ by the COP of the heating heat pump given the EFT at the time:

$$
\mathrm{P}_{H_{t}}=\frac{\operatorname{load}_{H_{t}}}{\mathrm{COP}_{H_{t}}}
$$

The power of the cooling heat pump is calculated similarly:

$$
\mathrm{P}_{C_{t}}=\frac{\operatorname{load}_{C_{t}}}{\mathrm{COP}_{C_{t}}}
$$

5. The heat absorbed from the building loop by the heat pump in heating mode at time $t$ is calculated by subtracting the power of the heating heat pump from the total heating load:

$$
\mathrm{H}_{\mathrm{abs}}=\operatorname{load}_{H_{t}}-\mathrm{P}_{H_{t}}
$$

The heat rejected to the building loop by the heat pump in cooling mode at time $t$ is calculated by adding the power of the cooling heat pump to the cooling load:

$$
\mathrm{H}_{\mathrm{rej}}=\operatorname{load}_{C_{t}}+\mathrm{P}_{C_{t}}
$$

The net impact of the heating and cooling heat pumps is then calculated by subtracting the heat absorbed from the loop from the heat rejected to the loop:

$$
\mathrm{H}_{\mathrm{net}}=\mathrm{H}_{\mathrm{rej}}-\mathrm{H}_{\mathrm{abs}}
$$

6. Pump flow rate is then calculated. If the user specifies a variable-speed pump, flow rate through the heating heat pump is calculated using the current heating load and the user-specified nominal pump flow rate. The flow rate through the cooling heat pump is calculated in the same manner, and the total loop flow rate is the sum of 
the heating and cooling flow rates. If the user specifies a constant speed pump, the pump flow rate is set to the design pump flow rate if there is a heating or cooling load, and to zero otherwise.

7. Next, the temperature of the heat exchanger fluid leaving the heat pumps is calculated from the net heat pump energy and loop flow rate.

8. Pump power can then be determined from the cubic relationship between normalized pump flow rated and normalized pump power:

$$
\text { Power }=\text { Rated Power }\left(\frac{\text { Flow Rate }}{\text { Nominal Flow Rate }}\right)^{3}
$$

$30 \%$ of the calculated pump power is assumed to end up as heat gain to the fluid, and the resulting temperature of the fluid leaving the pump is calculated. (The loop pump is located downstream from the heat pumps and upstream of the ground heat exchanger.)

9. The TRNDST ground heat exchanger model is then called with the following inputs: EFT, flow rate, and ambient temperature. The ground heat exchanger model calculates the leaving fluid temperature and the thermal history of the ground.

10. Steps 4 to 9 are repeated for each time step of the entire analysis period.

11. The maximum and minimum heat pump EFTs during the analysis period are recorded. These values are compared to user-specified requirements, and the size of the ground heat exchanger is adjusted until design conditions are met. Both the maximum and minimum conditions are checked and the resulting ground heat exchanger size is the larger of the required sizes. This process of checking temperatures and resizing the ground heat exchanger is governed by a Newton's Method algorithm that uses successive guesses to converge to a result. Steps 4 to 10 are repeated each time the ground heat exchanger size is adjusted.

The inherent assumption in this program is that there is enough thermal inertia in the system so that the EFT at the heat pump at time step $t+1$ is the same as the leaving fluid temperature at the ground heat exchanger at time step $t$. This assumption allows the program to avoid iterating each time step, greatly increasing simulation speed. This assumption has been tested through more detailed modeling in the base TRNSYS software.

To improve accuracy, the number of time steps per hour can be increased from 1 to 60 . Values of one time step per hour will result in fast solutions but may sacrifice some accuracy, whereas values of 60 time steps per hour yield highly accurate results at the expense of simulation time.

When all constraints have been satisfied, the program outputs the following results for the entire analysis period: ground heat exchanger size, power consumption, hourly energy flows, hourly average heat pump EFTs, and various peak conditions. 
The output power consumption (by time step) is set as the operating penalty for installing the GSHP system. REopt makes a binary decision on whether or not to install the optimally sized GSHP system, trading off thermal savings against the incurred electricity penalty. As noted above, smaller systems to meet partial heating and cooling loads are not considered unless the loads passed to the GSHP model are preprocessed.

\section{Resource Data}

The GSHP model in REopt uses data from the following sources:

- Ambient temperature. TMY3 measurements from the 1991-2005 National Solar Radiation Database. Site location is mapped to the closest measurement station across 1,020 locations in the continental United States

- Hourly heating and cooling loads. Closest matching TMY thermal energy consumption profile from EnergyPlus simulations of 16 DOE commercial reference building types across 15 climate zones.

- Heat pump COP. Performance curves based on EnergyPlus simulations.

- Technology parameters. TRNSYS estimates (see Table 19). 
Table 19. Typically Assumed GSHP Input Parameter Values

\begin{tabular}{|c|c|c|}
\hline Required Input & Units & Default Value \\
\hline Nominal Borehole Depth & $\mathrm{m}$ & 76.2 \\
\hline Depth of Ground Heat Exchanger Headers Below Grade & $\mathrm{m}$ & 1.22 \\
\hline Distance Between Boreholes & $\mathrm{m}$ & 6.096 \\
\hline Borehole Radius & $\mathrm{m}$ & 0.0762 \\
\hline Outer Radius of Individual U-Tube Pipe & $\mathrm{m}$ & 0.0167 \\
\hline Inner Radius of Individual U-Tube Pipe & $\mathrm{m}$ & 0.0135 \\
\hline Thermal Conductivity of Pipe Material & $\mathrm{kJ} / \mathrm{hmK}$ & 1.62 \\
\hline $\begin{array}{l}\text { Distance Between Centers of Upwards and Downwards U- } \\
\text { Tube Legs }\end{array}$ & $\mathrm{m}$ & 0.1016 \\
\hline Soil Thermal Conductivity & $\mathrm{kJ} / \mathrm{hmK}$ & 8.72 \\
\hline Soil Density & $\mathrm{kg} / \mathrm{m}^{3}$ & 2500 \\
\hline Soil Specific Heat & $\mathrm{kJ} / \mathrm{kg} \mathrm{K}$ & 1 \\
\hline Borehole Grout Thermal Conductivity & $\mathrm{kJ} / \mathrm{hmK}$ & 4.98 \\
\hline Average Soil Surface Temperature Over the Year & ${ }^{\circ} \mathrm{C}$ & 18.73 \\
\hline Amplitude of Soil Surface Temperature Over the Year & $\Delta^{\circ} \mathrm{C}$ & 11.46 \\
\hline Day of Minimum Soil Surface Temperature & day & 35 \\
\hline Ground Heat Exchanger Fluid Type & - & water \\
\hline Specific Heat of the Ground Heat Exchanger Fluid & $\mathrm{kJ} / \mathrm{kg} \mathrm{K}$ & 4.182 \\
\hline Density of the Ground Heat Exchanger Fluid & $\mathrm{kg} / \mathrm{m}^{3}$ & 1000 \\
\hline Nominal Heat Pump Flow Rate & gpm/ton & 2.5 \\
\hline Nominal Pump Power & W/gpm & 15 \\
\hline $\begin{array}{l}\text { Pump Option ( } 1 \text { for variable-speed pump, } 0 \text { for constant- } \\
\text { speed pump) }\end{array}$ & & 1 \\
\hline $\begin{array}{l}\text { Maximum allowable return fluid temperature from the } \\
\text { ground loop }\end{array}$ & ${ }^{\circ} \mathrm{C}$ & 35 \\
\hline $\begin{array}{l}\text { Minimum Allowable Return Fluid Temperature From the } \\
\text { Ground Loop }\end{array}$ & ${ }^{\circ} \mathrm{C}$ & 7 \\
\hline Number of Simulation Time Steps per Hour (1..60) & & 1 \\
\hline
\end{tabular}




\section{Assumptions}

The TRNSYS software makes the following assumptions when modeling GSHPs in REopt:

- There is one u-tube per borehole.

- All boreholes are in parallel.

- The ground is undisturbed at the start of the simulations.

- There is no insulation on the top, sides, or bottom of the ground heat exchanger.

- The soil is isothermal at the start of the simulations at the user-provided value.

- The soil is homogeneous.

The values assumed for the main inputs defining the GSHP system are listed in Table 19 and other technology specifications are summarized in Table 20. GSHPs are not limited by space availability.

Table 20. GSHP - Main Technology Data Sources and Assumptions

\begin{tabular}{ll}
\hline Resource Data Source & TMY3 \\
\hline Conventional Cooling COP & 2.5 \\
\hline & Method Dependent: \\
Conventional Heating COP & Electric heat pumps: 2.5 \\
& Electric resistance heating: 1.0 \\
& Natural gas or heating oil: 0.9 \\
\hline Capital and O\&M Costs & See Appendix A \\
\hline
\end{tabular}




\section{Model Parameters, Variables, and Equations}

We define here indices and sets, parameters, and variables, in that order, and then state the objective function and the constraints. We choose capital letters to represent sets, lowercase letters to represent parameters, and uppercase letters to represent variables; in the latter case, $Z$ and $Y$ variables are binary, and represent design and operational decisions, respectively. $X$ and $W$ variables represent continuous decisions, e.g., quantities of energy. All subscripts denote indices. Names with the same "stem" are related, and superscripts and "decorations" (e.g., hats, tildes) differentiate the names with respect to (for example) various indices included in the name or maximum and minimum values for the same parameter.

\subsection{Indices and Sets}

- $s \in \mathcal{S}$ : set of segments defining the capital costs

- $c \in \mathcal{C}$ : set of technology classes $(c=\beta$, SHW, SVP, LFG, WTE, W, PV, GSHP)

- $t \in \mathcal{T}$ : set of technologies

- $t \in \hat{\mathcal{T}}_{c}$ : set of technologies that belong to technology class $c$

- $t \in \tilde{\mathcal{T}}_{d}$ : set of technologies that can satisfy demand type $d$

- $t \in \mathcal{T}^{C H P^{M}}$ : set of technologies that supply mandatory $(\mathrm{M})$ combined heat and power (CHP), these are either waste to energy, landfill gas, or biomass

- $t \in \mathcal{T}^{C H P^{O}}$ : set of technologies that supply optional $(\mathrm{O})$ combined heat and power (CHP), these are either waste to energy, landfill gas, or biomass

- $d \in \mathcal{D}$ : set of demands (or loads) 1...6, where 1 is the electric load, 2 is natural gas, 3 is propane, and so on

- $d \in \mathcal{D}^{E}$ : set of demands being served through electric generation

- $d \in \mathcal{D}^{E^{o s}}$ : set of demands being served through electric generation for use on-site (os)

- $d \in \mathcal{D}^{E^{s b}}$ : set of demands being served through electric generation to be sold back $(\mathrm{sb})$

- $d \in \mathcal{D}^{T}$ : set of demands being served through thermal generation

- $h \in \mathcal{H}$ set of time steps

- $h \in \mathcal{H}_{r}$ set of time steps in ratchet $r$

- $h \in \mathcal{H}_{m}$ set of time steps in month $m$

- $l \in \mathcal{L}:$ set of locations 
- $l \in \mathcal{L}^{z}$ : set of locations at which net-zero electricity is required

- $v \in \mathcal{V}$ : set of net metering levels

- $v \in \hat{\mathcal{V}}_{t}$ : set of net metering levels for technology $t$

- $u \in \mathcal{U}$ : set of fuel bins

- $m \in \mathcal{M}$ : set of months

- $m \in \mathcal{M}^{L B}:$ set of look-back months

- $r \in \mathcal{R}$ : set of ratchets

\subsection{Parameters}

\section{- Counting parameters}

$\star n^{\dot{p}}$ : number of points defining capital costs (unitless)

\section{- Losses, factors, and ratios}

* $f_{d t l h}^{p}$ : hourly capacity factor for demand $d$ for technology $t$ at location $l$ in time step $h$ (unitless)

$\star f_{t}^{p l}$ : power loss factor for technology $t$ (unitless)

* $f_{t l h}^{E}$ : increased electric factor as a result of technologies with an electric penalty (SHW and SVP) for technology $t$ at location $l$ in time step $h$ (unitless)

$\star f_{l}^{\eta}$ : existing heating efficiency factor at location $l$ (unitless)

* $\underline{f}_{t}^{c o}$ : cogeneration electric minimum turndown for technology $t(\%)$

$\star f_{t}^{\frac{\sigma}{t}}$ : turbine downsize factor for technology $t$ (unitless)

$\star f_{l t d u}^{M}$ : variable fuel consumption per times tep at location $l$ for technology $t$ for demand $d$ for fuel bin $u$

$\star f_{l t d u}^{B}$ : fixed fuel consumption per time step at location $l$ for technology $t$ for demand $d$ for fuel bin $u$

$\star r_{t}^{t c o e}$ : ratio of mandatory thermal to electric generation for technology $t$ (unitless)

$\star f_{l}^{l b}$ : the look-back percent of demand for location $l$

\section{- Demand and supply parameters}

$\star \delta_{l}$ : annual electric load at location $l(\mathrm{kWh})$ 
$\star \bar{\delta}_{l}$ : total maximum annual electric demand at location $l(\mathrm{~kW})$

$\star \hat{\delta}_{d l}$ : total fuel demand capacity for demand $d$ at location $l(\mathrm{~kW})$

$\star q_{l t u}^{U}$ : the amount of fuel available in location $l$ for technology $t$ for fuel bin $u$

\section{- Incentives}

$\star \bar{i}_{t l}$ : maximum production incentive at location $l$ for technology $t(\$)$

$\star i_{d t l}^{r}$ : production incentive rate for demand $d$ at location $l$ for technology $t$ $(\$ / \mathrm{kWh})$

$\star \bar{i}_{t l}^{\sigma}$ : maximum system size eligible for a production incentive at location $l$ for technology $t(\mathrm{~kW})$

\section{- Costs}

$\star c_{l t n^{p}}^{K x}: x$-value (i.e., system size) capital cost for technology $t$ and point $n^{\dot{p}}(\mathrm{~kW})$

$\star c_{l t n^{p}}^{K y}: y$-value (i.e., cost at a given system size) capital cost for technology $t$ and point $n^{\dot{p}}(\$)$

$\star c_{d t l}^{o}$ : operating cost for demand $d$ of technology $t$ at location $l(\$ / \mathrm{kWh})$

$\star c_{l}^{f} t$ : fixed cost for technology $t$ at location $l(\$)$

$\star c_{t l}^{o m}$ : operating and maintenance cost per unit system size at location $l$ for technology $t(\$ / \mathrm{kW})$

$\star c_{d t l h}^{e}$ : sellback cost for demand $d$ of technology $t$ at location $l$ in time step $h$ $(\$ / \mathrm{kWh})$

$\star c_{t s}^{K A}$ : capital cost coefficient A (slope) for technology $t$ in segment $s(\$ / \mathrm{kWh})$

$\star c_{t s}^{K B}$ : capital cost coefficient B ( $y$-intercept) for technology $t$ in segment $s(\$)$

$\star y_{t s}^{K}: y$-intercept for capital cost calculations array for technology $t$ in segment $s$ $(\$)$

$\star c_{\text {ltuh }}^{U}$ : the cost of fuel in location $l$ for technology $t$ for fuel bin $u$ in time step $h$

$\star c_{l r}^{D}$ : the cost of demand at location $l$ for ratchet $r$

$\star c_{l m}^{D^{m}}$ : the cost of demand at location $l$ for month $m$

$\star c_{l}^{b^{k W}}$ : the capital cost of the battery per $\mathrm{kW}$ at location $l(\$ / \mathrm{kW})$

$\star c_{l}^{b^{k W h}}$ : the capital cost of the battery per $\mathrm{kWh}$ at location $l(\$ / \mathrm{kWh})$ 


\section{- System sizing and performance}

$\star b_{t l}^{\bar{\sigma}}$ : bound on system size for technology $t$ at location $l(\mathrm{~kW})$

$\star b_{t}^{\frac{\sigma}{t}}$ : minimum values for sub-technology $t(\mathrm{~kW})$

$\star b \frac{\sigma}{l t}$ : minimum values for technology $t$ in location $l(\mathrm{~kW})$

$\star b_{d l h}^{p}$ : bound on production size for demand $d$ at location $l$ in time step $h(\mathrm{~kW})$

$\star b_{d l h}^{\bar{p}}$ : bound on maximum production size for demand $d$ at location $l$ in time step $h(\mathrm{~kW})$

$\star b_{l v}^{c n m}$ : capacity for net metering level $v$ at location $l(\mathrm{~kW})$

$\star b_{d l h}^{p D H W}$ : bound on domestic hot water (DHW) production for demand $d$ at location $l$ in time step $h(\mathrm{~kW})$

$\star b_{d l h}^{S H}$ : bound on space heat production for demand $d$ at location $l$ in time step $h$ $(\mathrm{kW})$

$\star b_{l c}^{\overline{\bar{\sigma}}}$ : bound on technology class, largest possible size for technology class $c(\mathrm{~kW})$

$\star \underline{m}_{t}:$ minimum turndown for technology $t$ (unitless)

\section{- Storage parameters}

$\star w_{l}^{\bar{b}}$ : the maximum size of the battery $(\mathrm{kWh})$

$\star w_{l}^{\underline{b}}$ : the minimum size of the battery $(\mathrm{kWh})$

$\star b_{l}^{\bar{b}}$ : the maximum size of the battery $(\mathrm{kW})$

$\star f_{l t d}^{b}$ : roundtrip inverter efficiency

$\star t_{l}^{\underline{b}}$ : the minimum SoC of the battery at location $l$

\subsection{Decision Variables}

\section{- Binary variables}

$\star Z_{l}^{S H W}: 1$ if the technology is SHW at location $l, 0$ otherwise

$\star Z_{l}^{S V P}: 1$ if technology the technology is SVP at location $l, 0$ otherwise

$\star Z_{l}^{G S H P}: 1$ if technology $t$ is GSHP at location $l, 0$ otherwise

$\star Z_{t l}^{p}: 1$ if we build technology $t$ at location $l, 0$ otherwise

$\star Z_{t}^{\sigma}: 1$ if technology $t$ is of acceptable size, 0 otherwise 
$\star Z_{t l}^{\bar{\sigma}}: 1$ if technology $t$ is above the size at which we obtain a production incentive at location $l, 0$ otherwise

$\star Z_{l t c}: 1$ if at location $l$ from technology class $c$ we select technology $t \in \mathcal{T}_{c}, 0$ otherwise

$\star Y_{l v}: 1$ of we operate at net metering level $v$ at location $l, 0$ otherwise

* $Y_{t l h}^{o}: 1$ if technology $t$ is operational at location $l$ in time step $h, 0$ otherwise

$\star \hat{Y}_{l t}^{o}: 1$ if technology $t$ is operational, 0 otherwise

$\star \dot{Y}_{t l s}: 1$ if for technology $t$ at location $l$ we are in segment $s$ of the cost curve, 0 otherwise

* $Y_{l t h}^{c}: 1$ if technology $t$ at location $l$ in time step $h$ is an operational CHP optional technology, 0 otherwise

$\star Z_{l h}^{\hat{b}}: 1$ if in time step $h$ the battery is being discharged, 0 otherwise

$\star Z_{l h}^{\check{b}}: 1$ if in time step $h$ the battery is being charged, 0 otherwise

\section{- Nonnegative variables}

$\star \hat{X}_{d t l h s}^{q}$ : rated power supplied for demand $d$ and technology $t$ at location $l$ in time step $h$ in segment $s(\mathrm{~kW})$

$\star X_{d t l h s}^{E}$ : extra electric power consumed by a technology with an electric penalty (SHW and SVP) for demand $d$ and technology $t$ at location $l$ in time step $h$ in segment $s(\mathrm{~kW})$

$\star X_{t l s}^{\sigma}$ : system size for technology $t$ at location $l$ operating in segment $s(\mathrm{~kW})$

$\star X_{l t u}^{U}$ : amount of fuel used at location $l$ for technology $t$ for fuel bin $u$ (fuel unit)

$\star X_{l t u}^{U^{c}}$ : total cost of fuel used at location $l$ for technology $t$ for fuel bin $u(\$)$

$\star I_{t l}$ : production incentive value for technology $t$ at location $l(\$)$

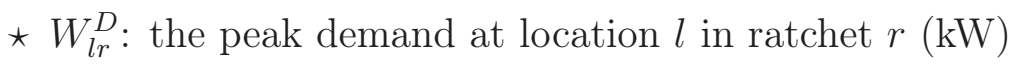

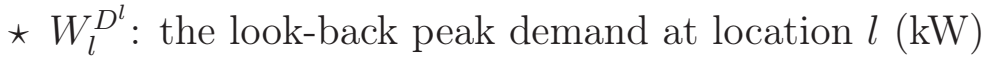

$\star W_{l m}^{D^{m}}$ : the monthly peak demand at location $l$ for month $m(\mathrm{~kW})$

$\star W_{l}^{b^{k W}}$ : battery system size $(\mathrm{kW})$ at location $l(\mathrm{~kW})$

$\star W_{l}^{b^{k W h}}$ : battery system size $(\mathrm{kWh})$ at location $l(\mathrm{kWh})$

* $X_{l h}^{\breve{b}}$ : power supplied to the battery in times tep $h$ at location $l(\mathrm{~kW})$

$\star X_{l h}^{\hat{b}}$ : power supplied from the battery in time step $h$ at location $l(\mathrm{~kW})$ 
$\star X_{l h}^{b}$ : the amount of energy stored in the battery at location $l$ in time step $h$ $(\mathrm{kWh})$

\section{- Auxiliary (and fixed) variables}

$$
\begin{aligned}
& \star c_{t s}^{K A}=\frac{c_{t n p}^{K y}-c_{t, n}^{K y}-1}{c_{t n^{p}}^{K x}-c_{t, n^{p}}^{K x}}(\$ / \mathrm{kWh}) \\
& \star c_{t s}^{K B}=c_{t, n^{p}-1}^{K y}(\$) \\
& \star y_{t s}^{K}=c_{t n^{p}}^{K y}-c_{t s}^{K A} * c_{t n^{p}}^{K x}(\$)
\end{aligned}
$$

\subsection{Objective Function}

The objective function minimizes the sum of (1) capital costs, (2) variable O\&M costs (based on energy produced), (3) demand costs, (4) battery costs, (5) increased electric costs (e.g., SWH pump consumption), (6) fixed O\&M costs (based on system size), (7) fixed costs, and (8) fuel costs, minus (9) production incentives.

$$
\begin{array}{r}
\min \sum_{t \in \mathcal{T}, l \in \mathcal{L}, s \in \mathcal{S}} c_{t s}^{K A} \cdot X_{t l s}^{\sigma}+y_{t s}^{K} \cdot \dot{Y}_{t l s}+ \\
\sum_{t \in \mathcal{T}, l \in \mathcal{L}, d \in \mathcal{D}, h \in \mathcal{H}, s \in \mathcal{S}} \cdot f_{d t l h}^{p} \cdot\left(c_{d t l}^{o}+c_{d t l h}^{e}\right) \cdot \hat{X}_{d t h s}^{q}+ \\
\sum_{l \in \mathcal{L}, r \in \mathcal{R}} W_{l r}^{D} \cdot c_{l r}^{D}+\sum_{l \in \mathcal{L}, m \in \mathcal{M}} W_{l m}^{D^{m}} \cdot c_{l m}^{D^{m}}+ \\
\sum_{l \in \mathcal{L}} W_{l}^{b^{k W h}} \cdot c_{l}^{b^{k W h}}+\sum_{l \in \mathcal{L}} W_{l}^{b^{k W}} \cdot c_{l}^{b^{k W}}+ \\
\sum_{t \in \mathcal{T}, l \in \mathcal{L}, d \in \mathcal{D}^{E^{o s}}, h \in \mathcal{H}, s \in \mathcal{S}} c_{d t l h}^{e} \cdot X_{d t l h s}^{E}+ \\
\sum_{t \in \mathcal{T}, l \in \mathcal{L}, s \in \mathcal{S}} c_{t l}^{o m} \cdot X_{t l s}^{\sigma}- \\
\sum_{t \in \mathcal{T}, l \in \mathcal{L}} I_{t l}+ \\
\sum_{t \in \mathcal{T}, l \in \mathcal{L}} c_{l}^{f} \cdot Z_{t l}^{p}+ \\
\sum_{l t u} X_{l t u}^{U^{c}}
\end{array}
$$

\subsection{Constraints}

This section contains both mathematical notation and text descriptions for all constraints in the model. In general, the text descriptions are written to convey the spirit of the 
constraint and may not address every index in for all or summation statements when they are not central to how the constraint operates. For complete sets of indices included in the constraint, please refer to the mathematical notation.

\subsubsection{Load Constraints}

The following section describes the load constraints.

- (5.5.1.1) requires that across all technologies except SHW, for every time step the amount of electricity offsetting on-site demand must be greater than or equal to the sum of the site load and the extra electricity associated with technologies that consume electricity in their operation.

- (5.5.1.2) requires that across all technologies except SHW and all fuels except electricity, for every time step the total energy supplied must be less than or equal to the site load for that fuel.

- (5.5.1.3) requires that for all fuels except electricity, the total energy supplied for each fuel (summed across all time steps) must be greater than or equal to the annual load for the fuel.

- (5.5.1.4) requires that for all CHP technologies and all fuels except electricity, for every time step the capacity (not scaled by production factors) must be less than the site thermal load.

- (5.5.1.5) requires that in each time step, the energy production from SHW does not exceed the domestic hot water load.

- (5.5.1.6) requires that in each time step, the energy production from SVP does not exceed the space heating load.

- (5.5.1.7) requires that across all technologies and all fuels, for every time step the amount of energy offsetting on-site demand must be less than or equal to the maximum load (maximum of site load and DHW load) plus extra electricity associated with technologies that consume electricity in their operation for electric load.

- (5.5.1.8) Requires that the sum of all electricity offsetting on-site demand and exported under net metering $(\mathrm{LD}=1 \mathrm{~W})$ be less than the annual electric load.

- (5.5.1.9) Establishes the amount of extra electricity required by technologies that consume electricity in their operation, as defined by how they are dispatched in the model.

$$
\sum_{t \in \mathcal{T} \backslash \hat{\mathcal{T}}_{S H W}, s \in \mathcal{S}, u \in \mathcal{U}} f_{d t l h}^{p} \cdot \hat{X}_{d t l h s u}^{q}+X_{l h}^{\hat{b}} \geq b_{d l h}^{p}+\sum_{t \in \mathcal{T}, s \in \mathcal{S}} X_{d t l h s}^{E}
$$




$$
\begin{aligned}
& -\sum_{t \in \mathcal{T} S H W, s \in \mathcal{S}, u \in \mathcal{U}} f_{d t l h}^{p} \cdot \hat{X}_{d t l h s u}^{q} \forall d \in \mathcal{D}^{E^{o s}}, l \in \mathcal{L}, h \in \mathcal{H} \\
& \sum_{t \in \tilde{\mathcal{T}}_{d} \backslash \mathcal{T} S H W} f_{d t \in \mathcal{S}, u \in \mathcal{U}}^{p} \cdot \hat{X}_{d t l h s u}^{q} \leq b_{d l h}^{p} \quad \forall d \in \mathcal{D} \backslash \mathcal{D}^{E^{o s}}, l \in \mathcal{L}, h \in \mathcal{H} \\
& \sum_{t \in \mathcal{T}, h \in \mathcal{H}, s \in \mathcal{S}, u \in \mathcal{U}} \hat{\delta}_{d l} \geq f_{d t l h}^{p} \cdot \hat{X}_{d t l h s u}^{q} \quad \forall d \in \mathcal{D} \backslash \mathcal{D}^{E}, l \in \mathcal{L} \\
& \sum_{s \in \mathcal{S}, u \in \mathcal{U}} \hat{X}_{d t l h s u}^{q} \leq f_{l}^{\eta} \cdot b_{d l h}^{p} \quad \forall d \in \mathcal{D} \backslash \mathcal{D}^{E}, t \in \mathcal{T}^{C H P^{M}} \cup \mathcal{T}^{C H P^{O}}, l \in \mathcal{L}, h \in \mathcal{H} \\
& \sum_{s \in \mathcal{S}, u \in \mathcal{U}} f_{d t l h}^{p} \cdot \hat{X}_{d t l h s u}^{q} \leq b_{d l h}^{p D H W} \quad \forall d \in \mathcal{D}, t \in \hat{\mathcal{T}}_{S H W}, l \in \mathcal{L}, h \in \mathcal{H} \\
& \sum_{s \in \mathcal{S}, t \in \mathcal{T} S V P \cup \mathcal{T} G S H P \in \mathcal{U}} f_{d t l h}^{p} \cdot \hat{X}_{d t l h s u}^{q} \leq b_{d l h}^{S H} \quad \forall d \in \mathcal{D}, l \in \mathcal{L}, h \in \mathcal{H} \\
& \sum_{t \in \mathcal{T}_{d}, s \in \mathcal{S}, u \in \mathcal{U}} f_{d t l h}^{p} \cdot \hat{X}_{d t l h s u}^{q} \leq b_{d l h}^{\bar{p}}+\sum_{t \in \mathcal{T}, s \in \mathcal{S}} X_{d t l h s}^{E} \quad \forall d \in \mathcal{D} \backslash \mathcal{D}^{E}, l \in \mathcal{L}, h \in \mathcal{H} \\
& \sum_{t \in \mathcal{T} \backslash \mathcal{T}^{\text {grid }}, d \in \mathcal{D}^{E^{\text {os }} \cup \mathcal{D}^{E^{s b}}, h \in \mathcal{H}, s \in \mathcal{S}, u \in \mathcal{U}}} f_{d t l h}^{p} \cdot \hat{X}_{d t l h s u}^{q} \leq \bar{\delta}_{l}+\sum_{t \in \mathcal{T}, d \in \mathcal{D}^{E^{o s}}, h \in \mathcal{H}, s \in \mathcal{S}} X_{d t l h s}^{E} \forall l \in \mathcal{L} \\
& X_{d t l h s}^{E}=f_{t l h}^{E} \cdot \sum_{d \in \mathcal{D} \backslash \mathcal{D}^{E}, u \in \mathcal{U}} f_{d t l h}^{p} \cdot \hat{X}_{d t l h s u}^{q} \cdot\left(Z_{l}^{S H W}+Z_{l}^{S V P}\right)+f_{t l h}^{E} \cdot X_{t l s}^{\sigma} \cdot Z_{l}^{G S H P} \\
& \forall t \in \mathcal{T}, l \in \mathcal{L}, h \in \mathcal{H}, s \in \mathcal{S}
\end{aligned}
$$

\subsubsection{System Size Constraints}

The following section describes the system size constraints.

- (5.5.2.1) ensures that the system size for every technology cannot exceed the maximum size.

- (5.5.2.2) ensures that only one technology from each technology class may be present in the model.

- (5.5.2.3) constrains the binary for (5.5.2.2), ensuring that only one technology can exist in each technology class

- (5.5.2.4) ensures that the system size for the technology in each tech class cannot exceed the maximum technology class size.

- $(5.5 .2 .5)$ ensures that the system size for the technology in each tech class is greater than the minimum technology class size.

- (5.5.2.6) ensures that the system size for every technology is greater than the minimum technology size. 
- (5.5.2.7) defines the binary associated with ensuring the minimum subtechnology size.

- (5.5.2.8) ensures that if the technology is selected by the model, it must be larger than the subtechnology minimum size.

- (5.5.2.9) states that the energy capacity of the battery (kWh) cannot be larger than the maximum allowable capacity.

- (5.5.2.10) states that the energy capacity of the battery (kWh) cannot be less than the minimum allowable capacity.

- (5.5.2.11) states that the power capacity of the battery $(\mathrm{kW})$ cannot be greater than the maximum allowable capacity.

$$
\begin{aligned}
& X_{t l s}^{\sigma} \leq b_{t l}^{\bar{\sigma}} \quad \forall t \in \mathcal{T}, l \in \mathcal{L}, s \in \mathcal{S} \\
& \sum_{s \in \mathcal{S}} X_{t l s}^{\sigma} \leq b^{\bar{\sigma}_{t l}} \cdot Z_{l t c} \quad \forall c \in \mathcal{C}, t \in \hat{\mathcal{T}}_{c}, l \in \mathcal{L} \\
& \sum_{t \in \mathcal{T}} Z_{l t c} \leq 1 \quad \forall l \in \mathcal{L}, c \in \mathcal{C} \\
& \sum_{s \in \mathcal{S}, t \in \hat{\mathcal{T}}_{c}} X_{t l s}^{\sigma} \leq b_{l c}^{\overline{\bar{\sigma}}} \quad \forall c \in \mathcal{C}, l \in \mathcal{L} \\
& \sum_{t \in \mathcal{T}, s \in \mathcal{S}} b_{l c}^{\overline{\bar{\sigma}}} \leq X_{t l s}^{\sigma} \forall l \in \mathcal{L}, c \in \mathcal{C} \\
& \sum_{s \in \mathcal{S}} b_{l t}^{\underline{\sigma}} \leq X_{t l s}^{\sigma} \forall l \in \mathcal{L}, t \in \mathcal{T} \\
& \sum_{s \in \mathcal{S}} X_{t l s}^{\sigma} \leq b^{\bar{\sigma}} \cdot Z_{t}^{\sigma} \quad \forall t \in \mathcal{T}, l \in \mathcal{L} \\
& b_{t}^{\frac{\sigma}{t}}-\sum_{s \in \mathcal{S}} X_{t l s}^{\sigma} \leq b^{\bar{\sigma}} \cdot\left(1-Z_{t}^{\sigma}\right) \quad \forall t \in \mathcal{T}, l \in \mathcal{L} \\
& W_{l}^{b^{k W h}} \leq w_{l}^{\bar{b}} \quad \forall l \in \mathcal{L} \\
& W_{l}^{b^{k W h}} \geq w_{l}^{b} \quad \forall l \in \mathcal{L} \\
& W_{l}^{b^{k W}} \leq b_{l}^{\bar{b}} \quad \forall l \in \mathcal{L}
\end{aligned}
$$

\subsubsection{Production Constraints}

The following section describes the production constraints.

- (5.5.3.1) requires that for all technologies (excluding GSHP, generators, and mandatory thermal CHP technologies), the rated power supplied in each time step-summed across all loads-be less than or equal to the selected system size. 
- (5.5.3.2) requires that for mandatory thermal CHP technologies, the rated power supplied in each time step to adjust the electric load be less than or equal to the selected system size.

- (5.5.3.3) ensures that for mandatory thermal CHP technologies, the rated power supplied in each time step-summed across all loads-be less than or equal to the selected system size scaled by an appropriate factor.

- (5.5.3.4) ensures the rated power supplied from GSHP technology across all thermal loads cannot exceed the system size.

- (5.5.3.5) ensures that GSHP technology cannot produce electricity (all electricity requirements for technology is accounted for in the extra electric requirements constraint (5.5.1.9)).

$$
\begin{array}{r}
X_{t l s}^{\sigma} \geq \sum_{d \in \mathcal{D}, u \in \mathcal{U}} \hat{X}_{d t l h s u}^{q} \forall t \in \mathcal{T} \backslash \mathcal{T}^{C H P^{M}} \cup \mathcal{T}^{G S H P}, l \in \mathcal{L}, h \in \mathcal{H}, s \in \mathcal{S} \\
X_{t l s}^{\sigma} \geq \sum_{d \in \mathcal{D}^{E}} \hat{X}_{d t l h s u}^{q} \forall t \in \mathcal{T}^{C H P^{M}}, l \in \mathcal{L}, h \in \mathcal{H}, s \in \mathcal{S}, u \in \mathcal{U} \\
\sum_{d \in \mathcal{D}, s \in \mathcal{S}, u \in \mathcal{U}} \hat{X}_{d t l h s u}^{q} \leq f_{t}^{p l} \cdot \sum_{s \in \mathcal{S}} X_{t l s}^{\sigma} \quad \forall t \in \mathcal{T}^{C H P^{M}}, l \in \mathcal{L}, h \in \mathcal{H} \\
\sum_{d \in \mathcal{D}^{T}, u \in \mathcal{U}} \hat{X}_{d t l h s u}^{q} \leq X_{t l s}^{\sigma} \quad \forall t \in \mathcal{T}^{G S H P}, l \in \mathcal{L}, s \in \mathcal{S} \\
\sum_{d \in \mathcal{D}^{E} \backslash \mathcal{D}^{E^{o s}}, u \in \mathcal{U}} \hat{X}_{d t l h s u}^{q} \leq 0 \quad \forall t \in \mathcal{T}^{G S H P}, l \in \mathcal{L}, s \in \mathcal{S}
\end{array}
$$

\subsubsection{Capital Cost Constraints}

The following section describes the capital cost constraints.

- (5.5.4.1) ensures that for each technology we are operating in exactly one segment of the cost curve.

- (5.5.4.2) and (5.5.4.3) determine in which segment of the piecewise linear cost curve we are operating. This constraint sets the system size to zero if we are not in the appropriate segment of the cost curve for each technology and location, and otherwise sets the size to be between the appropriate bounds.

- (5.5.4.4) defines the binary that determines whether a technology is built (used in objective function to apply fixed costs for a technology).

$$
\sum_{s \in \mathcal{S}} \dot{Y}_{t l s}=1 \quad \forall t \in \mathcal{T}, l \in \mathcal{L}
$$




$$
\begin{array}{r}
X_{t l s}^{\sigma} \leq c_{l t n^{p}}^{K x} \cdot \dot{Y}_{t l s} \quad \forall t \in \mathcal{T}, l \in \mathcal{L}, n^{p} \in \mathcal{S} \\
X_{t l s}^{\sigma} \geq c_{l t, n^{p}-1}^{K x} \cdot \dot{Y}_{t l s} \quad \forall t \in \mathcal{T}, l \in \mathcal{L}, n^{p} \in \mathcal{S} \\
\sum_{s \in \mathcal{S}} X_{t l s}^{\sigma} \leq b_{l t}^{\bar{\sigma}} \cdot Z_{l t}^{p} \quad \forall t \in \hat{\mathcal{T}}, l \in \mathcal{L}
\end{array}
$$

\subsubsection{Minimum Turndown Constraints}

The following section describes the minimum turndown constraints.

- (5.5.5.1) requires that for all technologies and time steps, the amount of power supplied across all loads is zero if the technology is not operational in a given time step, and is unlimited otherwise.

- $(5.5 .5 .2)$ utilizes the binary defined in (5.5.5.1) to ensure that if the technology is operational in that time step, it is operating above the minimum turndown for that technology.

- (5.5.5.3) requires that for all technologies with a fixed minimum turndown across time steps, the amount of power supplied across all loads is zero if the technology is not operational and is unlimited otherwise.

- $(5.5 .5 .4)$ utilizes the binary defined in (5.5.5.3) to ensure that if the technology is operational it is operating above the minimum turndown for that technology.

- (5.5.5.5) requires that for all CHP-optional technologies and for all time steps, the amount of power supplied to the electric load is zero if the technology is not operational in a given time step, and is unlimited otherwise.

- $(5.5 .5 .6)$ utilizes the binary defined in (5.5.5.5) to ensure that if the technology is operational in that time step, it is operating above the minimum electrical turndown for that technology.

- (5.5.5.7) requires that for mandatory thermal CHP technologies, for every time step the rated electrical power supplied must equal the rated thermal energy supplied times a fixed ratio.

$$
\begin{array}{r}
\sum_{d \in \mathcal{D}, s \in \mathcal{S}, u \in \mathcal{U}} f_{t l d h}^{p} \cdot \hat{X}_{d t l h s u}^{q} \leq b_{l t}^{\bar{\sigma}} \cdot Y_{t h h}^{o} \quad \forall t \in \mathcal{T}, l \in \mathcal{L}, h \in \mathcal{H} \\
\sum_{s \in \mathcal{S}} \underline{m}_{t} \cdot X_{t l s}^{\sigma}-\sum_{d \in \mathcal{D}, s \in \mathcal{S}, u \in \mathcal{U}} \hat{X}_{d t l h s u}^{q} \leq b_{l t}^{\bar{\sigma}} \cdot\left(1-Y_{t l h}^{o}\right) \quad \forall t \in \mathcal{T}, l \in \mathcal{L}, h \in \mathcal{H} \\
\sum_{d \in \mathcal{D}, s \in \mathcal{S}, u \in \mathcal{U}} f_{t l d h}^{p} \cdot \hat{X}_{d t l h s u}^{q} \leq b_{l t}^{\bar{\sigma}} \cdot \hat{Y}_{l t}^{o} \quad \forall t \in \hat{\mathcal{T}}_{\beta 1} \cup \hat{\mathcal{T}}_{W T E 1}, l \in \mathcal{L}, h \in \mathcal{H} \\
\sum_{s \in \mathcal{S}} \underline{m}_{t} \cdot X_{t l s}^{\sigma}-\sum_{d \in \mathcal{D}, s \in \mathcal{S}, u \in \mathcal{U}} \hat{X}_{d t l h s u}^{q} \leq b_{l t}^{\bar{\sigma}} \cdot\left(1-\hat{Y}_{l t}^{o}\right) \quad \forall t \in \hat{\mathcal{T}}_{\beta 1} \cup \hat{\mathcal{T}}_{W T E 1}, l \in \mathcal{L}, h \in \mathcal{H}
\end{array}
$$




$$
\begin{array}{r}
\sum_{d \in \mathcal{D}^{E}, s \in \mathcal{S}, u \in \mathcal{U}} f_{d t l h}^{p} \cdot \hat{X}_{d t l h s u}^{q} \leq b_{l t}^{\bar{\sigma}} \cdot Y_{t l h}^{c} \quad \forall t \in \mathcal{T}^{C H P^{O}}, l \in \mathcal{L}, h \in \mathcal{H} \\
\sum_{s \in \mathcal{S}} \underline{f}_{t}^{c o} \cdot X_{t l s}^{\sigma}-\sum_{d \in \mathcal{D}^{E}, s \in \mathcal{S}, u \in \mathcal{U}} \hat{X}_{d t l h s u}^{q} \leq b_{l t}^{\bar{\sigma}} \cdot\left(1-Y_{t l h}^{c}\right) \quad \forall t \in \mathcal{T}^{C H P^{O}}, l \in \mathcal{L}, h \in \mathcal{H} \\
\sum_{d \in \mathcal{D}^{E}, s \in \mathcal{S}, u \in \mathcal{U}}^{q} \hat{X}_{d t l h s u}=\sum_{d \in \mathcal{D} \backslash \mathcal{D}^{E}, s \in \mathcal{S}, u \in \mathcal{U}} \hat{X}_{d t l h s u}^{q} \cdot r_{t}^{t c o e} \quad \forall t \in \mathcal{T}^{C H P^{M}}, l \in \mathcal{L}, h \in \mathcal{H}
\end{array}
$$

\subsubsection{Fuel Tracking Constraints}

The following section desscribes the fuel tracking constraints.

- (5.5.6.1) defines the amount of fuel used for each technology and fuel bin by summing over the all time steps, loads, and segments the energy produced times the fuel burn rate $(\mathrm{M})$, plus the fixed fuel use per time step (B) for each time step that the technology is on (operating).

- (5.5.6.2) requires that the amount of fuel used must be less than the fuel available for each technology and fuel bin.

- (5.5.6.3) defines the total fuel cost for each technology and fuel bin, again using the fuel burn rate (M), plus the fixed fuel use per time step (B) for each time step that the technology is on (operating).

$$
\begin{array}{r}
\sum_{h \in \mathcal{H}, d \in \mathcal{D}, s \in \mathcal{S}} f_{d t l h}^{p} \cdot \hat{X}_{d t l h s u}^{q} \cdot f_{l t d u}^{M}+\sum_{h \in \mathcal{H}, d \in \mathcal{D}} Y_{t l h}^{o} \cdot f_{l t d u}^{B}=X_{l t u}^{U} \forall h \in \mathcal{H}, t \in \mathcal{T}, u \in \mathcal{U} \\
X_{l t u}^{U} \leq q_{l t u}^{U} \forall h \in \mathcal{H}, t \in \mathcal{T}, u \in \mathcal{U} \\
\sum_{h \in \mathcal{H}, d \in \mathcal{D}, s \in \mathcal{S}} f_{d t l h}^{p} \cdot \hat{X}_{d t l h s u}^{q} \cdot f_{l t d u}^{M} \cdot c_{l t u h}^{U}+\sum_{h \in \mathcal{H}, d \in \mathcal{D}} Y_{t l h}^{o} \cdot f_{l t d u}^{B} \cdot c_{l t u h}^{U}= \\
X_{l t u}^{U^{c}} \forall l \in \mathcal{L}, t \in \mathcal{T}, u \in \mathcal{U}
\end{array}
$$

\subsubsection{Storage Constraints}

The following section describes the storage constraints.

- (5.5.7.1) initializes the state of charge for the battery in each location.

- (5.5.7.2) defines the amount of energy being delivered to the battery in each time step by summing energy supplied to the battery across all technologies and applying required storage efficiency derates. 
- (5.5.7.3) defines the state of charge of the battery in each location and time step as the energy stored in the battery in the previous time step, plus energy coming in, less energy going out.

- (5.5.7.4) ensures that the energy coming out of the storage system in each time step is less than the state of charge in the previous time step.

- (5.5.7.5) ensures that the state of charge is maintained above a minimum state of charge threshold.

- (5.5.7.6) requires that the inverter size be greater than the amount of electricity taken out of the battery in any time step.

- (5.5.7.7) requires that the inverter size be greater than the amount of electricity delivered to the battery in any time step.

- (5.5.7.8) requires that the energy capacity of the battery be greater than the amount of electricity stored in the battery in any time step.

- (5.5.7.9) defines whether the battery is charging in a given time step.

- (5.5.7.10) defines whether the battery is discharging in a given time step.

- (5.5.7.11) states that in each location and time step, the battery cannot be both charging and discharging.

$$
\begin{aligned}
& X_{l h}^{b}=t_{l}^{\underline{b}} \cdot \sum_{b \in \mathcal{B}} W_{l}^{b^{k W h}} \forall l \in \mathcal{L} \mid t=1 \\
& X_{h l}^{\check{b}}=\sum_{t \in \mathcal{T}, s \in \mathcal{S}, u \in \mathcal{U}} f_{l d t h}^{p} \cdot X_{l d t h s}^{q} \cdot f_{l t d}^{b} \quad \forall h \in \mathcal{H}, l \in \mathcal{L}, d \in \mathcal{D}^{E^{b}} \\
& X_{l h}^{b}=X_{l, h-1}^{b}+X_{l h}^{\check{b}}-X_{l h}^{\hat{b}} ; \quad \forall h \in \mathcal{H}, l \in \mathcal{L} \\
& X_{l h}^{\hat{b}} \leq X_{l, h-1}^{b} \quad \forall h \in \mathcal{H}, l \in \mathcal{L} \\
& t_{l}^{\underline{b}} \cdot W_{l}^{b} \leq X_{l h}^{b} \quad \forall h \in \mathcal{H}, l \in \mathcal{L} \\
& X_{l h}^{\check{b}} \leq W_{l}^{b^{k W}} \forall l \in \mathcal{L}, h \in \mathcal{H} \\
& X_{l h}^{\hat{b}} \leq W_{l}^{b^{k W}} \forall l \in \mathcal{L}, h \in \mathcal{H} \\
& X_{l h}^{b} \leq W_{l}^{b^{k W h}} \forall l \in \mathcal{L}, h \in \mathcal{H} \\
& X_{l h}^{\check{b}} \leq b_{l}^{\bar{b}} \cdot Z_{l h}^{\check{b}} \forall l \in \mathcal{L}, h \in \mathcal{H} \\
& X_{l h}^{\hat{b}} \leq b_{l}^{\bar{b}} \cdot Z_{h}^{\hat{b}} \forall l \in \mathcal{L}, h \in \mathcal{H} \\
& Z_{l h}^{\hat{b}}+Z_{l h}^{\check{b}} \leq 1 \forall l \in \mathcal{L}, h \in \mathcal{H}
\end{aligned}
$$




\subsubsection{Demand Rate Constraints}

The following section describes the demand rate constraints.

- (5.5.8.1) requires that the demand in each demand period be greater than or equal to the grid electricity consumed during the time steps in that demand period.

- (5.5.8.2) requires that the demand in each demand period be greater than or equal to the look-back demand (as defined by (5.5.8.4)) multiplied by a scaling factor.

- (5.5.8.3) defines the demand in each month as greater than or equal to the grid electricity consumed during the time steps in that month.

- (5.5.8.4) requires that the look-back demand is greater than the monthly demand (as defined in (5.5.8.3)) over the set of months in the look-back.

$$
\begin{array}{r}
W_{l r}^{D} \geq \sum_{s \in \mathcal{S}, d \in \mathcal{D}, u \in \mathcal{U}} \hat{X}_{d t h s u}^{q} \quad \forall l \in \mathcal{L}, t \in \mathcal{T}^{\text {grid }}, r \in \mathcal{R}, h \in \mathcal{H}_{r} \\
W_{l r}^{D} \geq f_{l}^{l b} \cdot W_{l}^{D^{l}} \quad \forall l \in \mathcal{L}, m \in \mathcal{M}, r \in \mathcal{R}, h \in \mathcal{H} \\
W_{l m}^{D^{m}} \geq \sum_{s \in \mathcal{S}, d \in \mathcal{D}, u \in \mathcal{U}} \hat{X}_{d t l h s u}^{q} \quad \forall l \in \mathcal{L}, t \in \mathcal{T}^{\text {grid }}, m \in \mathcal{M}, h \in \mathcal{H}_{m} \\
W_{l}^{D^{l}} \geq W_{l m}^{D^{m}} \quad \forall l \in \mathcal{L}, d \in \mathcal{D}, m \in \mathcal{M}^{L B}
\end{array}
$$

\subsubsection{Production Incentive Constraints}

The following section describes the production incentive constraints.

- (5.5.9.1)states that the total production incentive realized for each technology in each location must be less that the maximum production incentive for that technology and location if a production incentive is realized, and zero otherwise.

- (5.5.9.2) defines the production incentive based on the energy produced and places an upper bound on the production incentive value of the technology accordingly.

- (5.5.9.3) states that for all technologies, if the system size exceeds the maximum system size for production incentive then the production incentives are forfeit (as assessed in the objective function).

$$
\begin{aligned}
& I_{t l} \leq \bar{i}_{t l} \cdot Z_{t l}^{\bar{\sigma}} \quad \forall t \in \mathcal{T}, l \in \mathcal{L} \\
& I_{t l} \leq \sum_{d \in \mathcal{D}, h \in \mathcal{H}, s \in \mathcal{S}, u \in \mathcal{U}} f_{d t h}^{p} \cdot \hat{X}_{d t l h s U}^{q} \cdot i_{d t l}^{r} \quad \forall t \in \mathcal{T}, l \in \mathcal{L}
\end{aligned}
$$




$$
\sum_{s \in \mathcal{S}} X_{t l s}^{\sigma} \leq \bar{i}_{t l}^{\sigma}+b^{\bar{\sigma}} \cdot\left(1-Z_{t l}^{\bar{\sigma}}\right) \quad \forall t \in \mathcal{T}, l \in \mathcal{L}
$$

\subsubsection{Net Metering Constraints}

The following section describes the net metering constraints.

- (5.5.10.1) states that we must operate in only one net metering regime.

- $(5.5 .10 .2)$ requires that the sum of system sizes for all technologies that apply towards the net metering level is less than the net metering level if operating in that net metering level, and zero otherwise.

$$
\begin{array}{r}
\sum_{v \in \mathcal{V}} Y_{l v}=1 \quad \forall l \in \mathcal{L} \\
\sum_{t \in \mathcal{T}, s \in \mathcal{S}} f_{t}^{\sigma} \cdot X_{t l s}^{\sigma} \leq b_{l v}^{c n m} \cdot Y_{l v} \quad \forall l \in \mathcal{L}, v \in \hat{\mathcal{V}}_{t}
\end{array}
$$

\subsubsection{Net Zero Constraint}

The following section describes the net zero constraint.

- (5.5.11.1) states that across all electric loads, technologies (except the grid), time steps, segments, and fuel bins, the electricity produced must equal the annual electric load at the site (plus the electric penalty), forcing the site to meet (exactly) electric net zero.

$$
\sum_{d \in \mathcal{D}^{E}, t \in \mathcal{T} \backslash \mathcal{T}^{\text {grid }}, h \in \mathcal{H}, s \in \mathcal{S}, u \in \mathcal{U}} f_{d t l h}^{p} \cdot f_{l t d}^{b} \cdot \hat{X}_{d t l h s u}^{q}=\delta_{l}+\sum_{d \in \mathcal{D}^{E^{o s}}, t \in \mathcal{T}, h \in \mathcal{H}, s \in \mathcal{S}} X_{d t l h s}^{E} \forall l \in \mathcal{L}^{z}
$$




\section{A Appendix - Example Costs Assumptions (2016)}

This section lists example REopt technology cost assumptions. Values are updated annually.

Table A1. 2016 Default REopt Technology Cost Assumptions

\begin{tabular}{|c|c|c|}
\hline \multirow{4}{*}{ PV, Fixed Axis } & & $\$ 2.54 / \mathrm{W}-\mathrm{DC}$ for system sizes $0-200 \mathrm{~kW}$ \\
\hline & Marginal Installation Cost & $\$ 2.01 / \mathrm{W}-\mathrm{DC}$ for system sizes $200 \mathrm{~kW}-5 \mathrm{MW}$ \\
\hline & & $\$ 1.79 / \mathrm{W}-\mathrm{DC}$ for system sizes $>5 \mathrm{MW}$ \\
\hline & O\&M Cost & $\$ 0.020 / \mathrm{W}-$ year \\
\hline \multirow{4}{*}{ Wind } & & $\$ 2.42 / \mathrm{W}$ for system sizes $0-50 \mathrm{~kW}$ \\
\hline & Marginal Installation Cost & $\$ 2.38 / \mathrm{W}$ for system sizes $50-850 \mathrm{~kW}$ \\
\hline & & $\$ 1.75 / \mathrm{W}$ for system sizes $>850 \mathrm{~kW}$ \\
\hline & O\&M Cost & $\$ 0.035 / \mathrm{W}-$ year \\
\hline \multirow{2}{*}{ SWH } & Installation Cost & $\$ 141 / \mathrm{ft}^{2}$ \\
\hline & O\&M Cost & $1 \%$ of installed cost / year \\
\hline \multirow{2}{*}{ SVP } & Installation Cost & $\$ 31 / \mathrm{ft}^{2}$ \\
\hline & O\&M Cost & - \\
\hline \multirow{2}{*}{ GSHP } & Installation Cost & $\$ 1,000 / \mathrm{kW}$ \\
\hline & O\&M Cost & $\$ 12 / \mathrm{ft}^{2} /$ year \\
\hline \multirow{3}{*}{ Biomass (All) } & & $\$ 0 /$ ton (on-site resource) \\
\hline & Fuel Cost & $\$ 20.50$ / ton (resource within a 25 -mile radius) \\
\hline & & $\$ 32.50 /$ ton (resource within a 50 -mile radius) \\
\hline \multirow{6}{*}{$\begin{array}{l}\text { Biomass } \\
\text { (Electric } \\
\text { and CHP } \\
\text { Condensing) }\end{array}$} & & $\$ 26.78$ / W for system sizes $0-713 \mathrm{~kW}$ \\
\hline & Marginal Installation Cost & $\$ 8.04 / \mathrm{W}$ for system sizes $713 \mathrm{~kW}-6.67 \mathrm{MW}$ \\
\hline & & $\$ 1.83 / \mathrm{W}$ for system sizes $>6.67 \mathrm{MW}$ \\
\hline & & $\$ 2.47 / \mathrm{W}-$ year for system sizes $0-713 \mathrm{~kW}$ \\
\hline & Marginal O\&M Cost & $\begin{array}{l}\$ 0.82 / \mathrm{W}-\text { year for system sizes } \\
713 \mathrm{~kW}-6.67 \mathrm{MW}\end{array}$ \\
\hline & & $\$ 0.08 / \mathrm{W}-$ year for system sizes $>6.67 \mathrm{MW}$ \\
\hline
\end{tabular}




\begin{tabular}{|c|c|c|}
\hline \multirow{6}{*}{$\begin{array}{l}\text { Biomass } \\
\text { (CHP Back } \\
\text { Pressure) }\end{array}$} & & $\$ 26.92 / \mathrm{W}$ for system sizes $0-806 \mathrm{~kW}$ \\
\hline & Marginal Installation Cost & $\$ 8.84 / \mathrm{W}$ for system sizes $806 \mathrm{~kW}-5.59 \mathrm{MW}$ \\
\hline & & $\$ 2.25 / \mathrm{W}$ for system sizes $>5.59 \mathrm{MW}$ \\
\hline & & $\$ 2.46$ / W-year for system sizes $0-806 \mathrm{~kW}$ \\
\hline & Marginal O\&M Cost & $\begin{array}{l}\$ 0.89 / \mathrm{W}-\text { year for system sizes } \\
806 \mathrm{~kW}-5.59 \mathrm{MW}\end{array}$ \\
\hline & & $\$ 0.13 / \mathrm{W}-$ year for system sizes $>5.59 \mathrm{MW}$ \\
\hline \multirow{6}{*}{$\begin{array}{l}\text { Biomass } \\
\text { (Thermal) }\end{array}$} & & $\$ 5.80 / \mathrm{W}$ for system sizes $0-3.09 \mathrm{MW}$ \\
\hline & Marginal Installation Cost & $\$ 1.81 / \mathrm{W}$ for system sizes $3.09-22.75 \mathrm{MW}$ \\
\hline & & $\$ 0.51 / \mathrm{W}$ for system sizes $>22.75 \mathrm{MW}$ \\
\hline & & $\$ 0.62 / \mathrm{W}-$ year for system sizes $0-3.09 \mathrm{MW}$ \\
\hline & Marginal O\&M Cost & $\$ 0.22$ / W-year for system sizes $3.09-22.75 \mathrm{MW}$ \\
\hline & & $\$ 0.04 / \mathrm{W}-$ year for system sizes $>22.75 \mathrm{MW}$ \\
\hline \multirow{2}{*}{ LFG (All) } & Gas Cost & $\$ 1 / \mathrm{MMBtu}$ \\
\hline & Piping Cost & $\$ 346,200$ / mile \\
\hline \multirow{4}{*}{ LFG (Electric) } & & $\$ 5.65 / \mathrm{W}$ for system sizes $0-110 \mathrm{~kW}$ \\
\hline & Marginal Installation Cost & $\$ 2.56 / \mathrm{W}$ for system size $110 \mathrm{~kW}-3 \mathrm{MW}$ \\
\hline & & $\$ 2.41 / \mathrm{W}$ for system size $>3 \mathrm{MW}$ \\
\hline & O\&M Cost & $\$ 0.250 / \mathrm{W}-$ year \\
\hline \multirow{4}{*}{ LFG (CHP) } & & $\$ 6.10 / \mathrm{W}$ for system sizes $0-120 \mathrm{~kW}$ \\
\hline & Marginal Installation Cost & $\$ 2.88$ / W for system sizes $120 \mathrm{~kW}-3.6 \mathrm{MW}$ \\
\hline & & $\$ 2.74 / \mathrm{W}$ for system sizes $>3.6 \mathrm{MW}$ \\
\hline & O\&M Cost & $\$ 0.255 / \mathrm{W}-$ year \\
\hline \multirow{4}{*}{ LFG (Thermal) } & & $\$ 2.33 / \mathrm{W}$ for system sizes $0-267 \mathrm{~kW}$ \\
\hline & Marginal Installation Cost & $\$ 1.06 / \mathrm{W}$ for system size $267 \mathrm{~kW}-7.27 \mathrm{MW}$ \\
\hline & & $\$ 0.99 / \mathrm{W}$ for system size $>7.27 \mathrm{MW}$ \\
\hline & O\&M Cost & $\$ 0.250 / \mathrm{W}-$ year \\
\hline
\end{tabular}




\begin{tabular}{lll}
\hline & Installation Cost & $\$ 0.50 / \mathrm{Wh}$ \\
Energy & & $\$ 1.50 / \mathrm{W}$ \\
$\begin{array}{l}\text { Storage } \\
\text { (Lithium-Ion }\end{array}$ & Replacement Cost & $\$ 0.40 / \mathrm{Wh}$ \\
Battery) & & $\$ 0.40 / \mathrm{W}$ \\
& O\&M cost & - \\
\hline
\end{tabular}




\section{References}

Castillo, Enrique, Antonio J. Gonejo, Pablo Pedregal, Ricardo Garcia, and Natalia Alguacil. 2002. Building and Solving Mathematical Programming Models in Engineering and Science. New York.

Dobos, Aron P. 2014. PVWatts Version 5 Manual. Tech. rep. http://www.nrel.gov/docs/ fy14osti/62641.pdf.

Downing, S.D., and D.F. Socie. 1982. "Simple Rainflow Counting Algorithms." International Journal of Fatigue 4 (1): 31-40.

DSIRE. 2017. Database of State Incentives for Renewables \& Efficiency. NC Clean Energy Technology Center. http://www.dsireusa.org/.

EPA. 2017. Landfill Methane Outreach Program. https://www.epa.gov/lmop.

Fuller, Sieglinde K., and Stephen R. Petersen. 1995. Life-Cycle Costing Manual for the Federal Energy Management Program. Tech. rep. http://fire.nist.gov/bfrlpubs/build96/ $\mathrm{PDF} / \mathrm{b} 96121 . p d f$.

Haaren, Rob van, Nickolas Themelis, and Nora Goldstein. 2010. "The State of Garbage in America: 17th Nationwide Survey of MSW Management in the US." BioCycle.

Klein, S.A. et al. 2017. TRNSYS 18: A Transient System Simulation Program. Solar Energy Laboratory, University of Wisonsin, Madison. http://sel.me.wisc.edu/trnsys.

Lavappa, Priya D., Joshua D. Kneifel, and Eric G. O’Rear. 2017. "Energy Price Indices and Discount Factors for Life-Cycle Cost Analysis - 2017 Annual Supplement to NIST Handbook 135." http://nvlpubs.nist.gov/nistpubs/ir/2017/NIST.IR.85-3273-32.pdf.

Milbrandt, A. 2005. "A Geographic Perspective on the Current Biomass Resource Availability in the United States." NREL Technical Report. http://www.nrel.gov/docs/ fy06osti/39181.pdf.

National Renewable Energy Laboratory. 1998. "Transpired Collectors (Solar Preheaters for Outdoor Ventilation Air)." Federal Technology Alert. http://www1.eere.energy.gov/ femp/pdfs/FTA_trans_coll.pdf.

Office of Energy Efficiency and Renewable Energy. 2017. Commercial Reference Buildings. https://energy.gov/eere/buildings/commercial-reference-buildings.

OpenEI. 2017. Utility Rate Database. http://en.openei.org/wiki/Utility_Rate_Database. 
Rushing, Amy S., Joshua D. Kneifel, and Barbara C. Lippiatt. 2013. Energy Price Indices and Discount Factors for Life-Cycle Cost Analysis. Tech. rep. http://ws680.nist.gov/ publication/get_pdf.cfm?pub_id $=914146$.

Safari, M., and C. Delacourt. 2011. "Simulation-Based Analysis of Aging Phenomena in a Commercial Graphite/LiFePO4 Cell." Journal of the Electrochemical Society 158 (12): A1436-1447.

Short, Walter, Dj Packey, and T Holt. 1995. A Manual for the Economic Evaluation of Energy Efficiency and Renewable Energy Technologies. Tech. rep. http://www.nrel.gov/ docs/legosti/old/5173.pdf.

Stanke, Dennis, et al. 2007. "ASHRAE Standard - Ventilation for Acceptable Indoor Air Quality." ANSI.

U.S. Census Bureau. 2002. County Business Patterns (CBP). www.census.gov/programssurveys/cbp/data/datasets.html.

USDA Forest Service. 2007. Timber Products Output Studies. www.fia.fs.fed.us/programfeatures/tpo.

Wilcox, S. 2007. National Solar Radiation Database 1991-2005 Update: User's Manual. Tech. rep. http://www.osti.gov/energycitations/product.biblio.jsp?osti_id $=901864$. 